\title{
QUANTIFICAÇÃO DE TECIDO CONJUNTIVO DO MÚSCULO CARDÍACO DE CÃES
}

Dissertação apresentada para obtenção do título de Mestre, junto à Faculdade de Medicina

Veterinária e Zootecnia da Universidade de São Paulo

\section{Departamento:}

Cirurgia

Área de Concentração:

Anatomia dos Animais Domésticos

Orientador:

Prof. Dr. Pedro Primo Bombonato 
DADOS INTERNACIONAIS DE CATALOGAÇÃO-NA-PUBLICAÇÃO

(Biblioteca da Faculdade de Medicina Veterinária e Zootecnia da Universidade de São Pauło)

T.1095 Benedicto, Hildebrando Gomes

FMVZ Quantificação de tecido conjuntivo do músculo cardiaco de cães /Hildebrando Gomes Benedicto.

$79 \mathrm{f}$ : : il.

Dissertação (mestrado em Anatomia dos Animais Domésticos) - Universidade de São Paulo. Faculdade de Medicina Veterinária e Zootecnia. Departamento de Cirurgia, São Paulo, 2002.

Área de concentração: Anatomia dos Animais Domésticos.

Orientador: Prof. Dr. Pedro Primo Bombonato.

Unitermos: 1.Cães. 2.Coração. 3.Miocárdio. 4. Tecido conjuntivo. 5.Colágeno. 


\section{AGRADECIMENTOS}

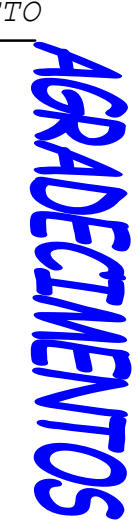

A DEUS

Por me dar vida, me mostrar a verdade e me conduzir pelo caminho correto. À Ele toda a Honra, toda a Glória, todo Louvor e toda a Majestade. 


\section{AGRADECIMENTOS}

\section{Ao Prof. Dr. Pedro Primo Bombonato}

Cada professor é singular no seu modo de ensinar, mesmo que existam métodos e técnicas estabelecidas para todos em função da pedagogia e da didática, cada um é individual e tem recursos próprios para adaptar os conhecimentos e aplicar as condições particulares, valorizando o aluno. A educação é o preparo para a vida, é ampliar os conhecimentos, é vocação. O ensino não é somente a transmissão de conhecimentos, é despertar o aluno, criar nele uma pré-disposição a aprender, motivar, desenvolver potencialidades, lapidar e conhecer o aluno, orientando sua aprendizagem.

O meu sincero agradecimento, com a certeza de que sem sua participação e, muitas vezes, intervenção esse trabalho não existiria.

Ao Pedro e família

O Senhor te abençoe e te guarde; o Senhor faça resplandecer o rosto sobre ti e tenha misericórdia de ti; o Senhor sobre ti levante o rosto e te dê a paz.

$\mathrm{Nm}$ 6.24-26 


\section{Agradecimentos}

A minha família que tem a todo momento mostrado compreensão ao meu trabalho.

A Faculdade de Medicina Veterinária e Zootecnia por ter suas portas abertas ao ensino e pesquisa.

Ao Curso de Pós-graduação em Anatomia dos Animais Domésticos e a cada um dos professores deste curso.

Aos todos os colegas de pós-graduação, pelo apoio: Marcelo Ismar, Moacir, Paulo, Paulo Brandão, Fernanda, Luciana, Selma, Marta, Annelise, Flávia, Assis.

Aos meus amigos, que estiveram orando por mim: Junior e Hosana; Fernanda; Marcos Bombonato; Joede; Léo e Valéria; Ailton e Márcia; Ely e Miriam.

Ao técnico do Laboratório de Histologia, Ronaldo, pela confecção das lâminas e auxílio na preparação dos corantes.

Aos técnicos Ednaldo e Diogo, pela ajuda.

Ao CNPQ pelo auxílio financeiro durante a realização deste curso. 


\section{Abreviaturas}

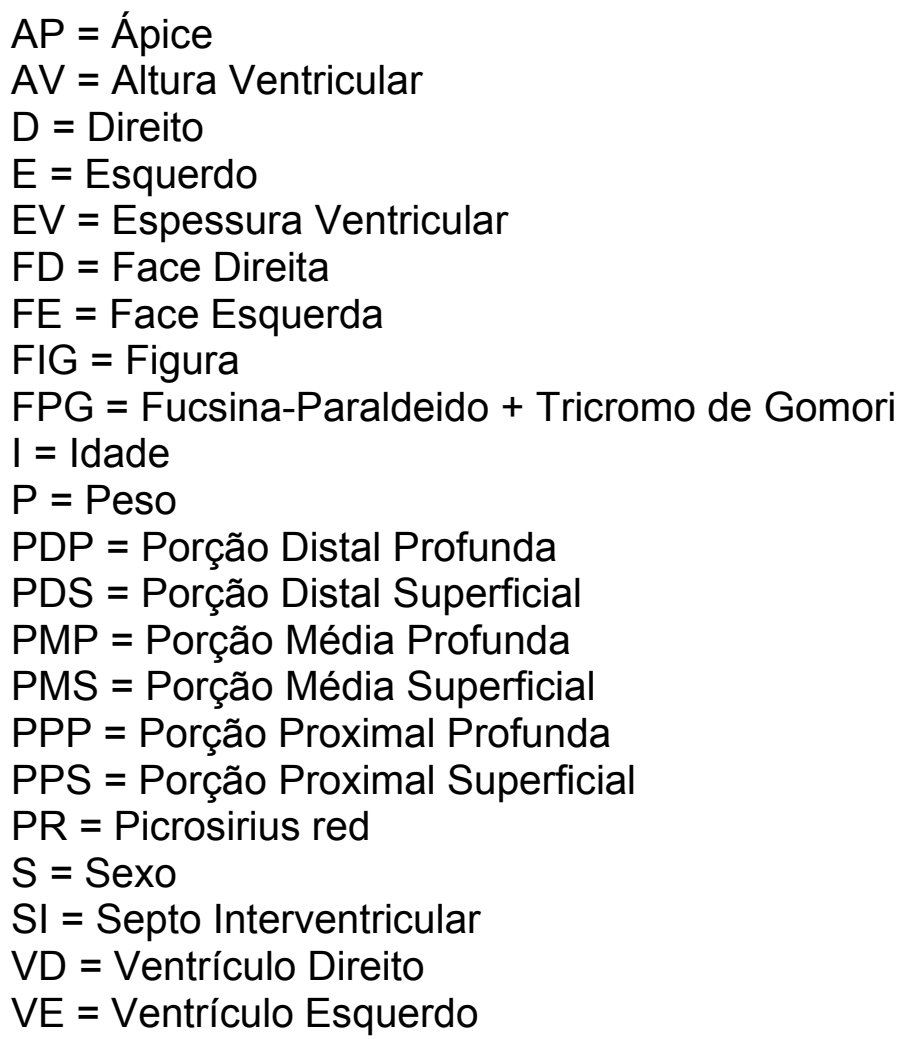




\section{RESUMO}

BENEDICTO, H. G. Quantificação de tecido conjuntivo do músculo cardíaco de cães. 2002. 79f. Dissertação (Mestrado em Anatomia dos Animais Domésticos) - Faculdade de Medicina Veterinária e Zootecnia, Universidade de São Paulo, São Paulo.

Objetivou-se, neste trabalho, estudar a proporção de tecido conjuntivo existente na fração ventricular direita e esquerda do músculo cardíaco de cães, buscando, através da morfometria, dados referentes a inter-relação entre o tecido conjuntivo e o tecido muscular cardíaco, para o conhecimento das relações anátomo-funcionais da estrutura cardíaca, característica de determinados processos ligados a diminuição do trabalho do órgão. Utilizou-se corações de cães SRD, machos e fêmeas, com idade entre 48 e 150 meses, pesando entre 18 e $30 \mathrm{Kg}$, sem alterações cardíacas, confirmado mediante exames eletrocardiográfico e ecocardiográfico. Preparou-se o material oriundo de três regiões ventriculares em relação a sua base, proximal, média e distal, tanto da face direita quanto da esquerda, segundo as técnicas histológicas convencionais e corados com Picrosirius red, Fucsina-Paraldeido e Tricromo de Gomori, para evidenciação das fibras conjuntivas. As lâminas foram analizadas com auxílio do Axioscópio Zeiss acoplado ao programa de análise de imagens KS-400 Zeiss. A quantidade de tecido conjuntivo no Ventrículo Esquerdo variou de 0,44 a $26,26 \%$; no Ventrículo Direito variou de 0,97 a $21,18 \%$; no ápice variou de 1,32 a $29,24 \%$ e no septo interventricular variou de 5,41 a $11,24 \%$. 
Os resultados obtidos mostram que há uma complexa rede de fibras conjuntivas envolvendo as fibras do tecido muscular cardíaco e que sua quantidade e disposição é muito variada, dependendo da região estudada.

Unitermos: Cães; Coração; Miocárdio; Tecido Conjuntivo; Colágeno. 
ABSTRACT

BENEDICTO, H. G. Quantification of connective tissue in dogs cardiac muscle. 2002. 79f. Dissertação (Mestrado em Anatomia dos Animais Domésticos) Faculdade de Medicina Veterinária e Zootecnia, Universidade de São Paulo, São Paulo.

The aim of this study was to evaluate the ratio of connective tissue on the right and left ventricule of the cardiac muscle in the dog. Throughout the morphometric study, we can gather information regarding the relationship between the connective and the muscle tissue, in order to find out the anatomic and functional relationship of the heart, which can provide information as for the diseases of the heart. In this study, we evaluated the heart of 6 dogs, males and females, from 48 to 150 months-old, whose weight ranged from 18 to 30 kilograms, with no heart diseases confirmed by eletrocardographic and echocardiographic examinations. We got sample from 3 different regions of the ventricule, on the proximal, medial and distal faces, both on the right and left parts. We used the Picrosirius red and Gomori's Trichrome to stain the material and bring out the connective fibers. We evaluated the slides by Axioscope Zeiss ${ }^{\circ}$ with program KS400 analyse of images. The amount of connective tissue on the left ventricule ranged from 0,44 to $26,26 \%$. On the right ventricule, it ranged from 0,97 to $21,18 \%$. On the apex, it ranged from 1,32 to $29,24 \%$ and on the septo interventricular, it 
ranged from 5,41 to $11,24 \%$. The results showed that there is a accureted connective fibers pattern surrounding the cardiac muscle tissue and it has an assorted amount and arrangement of fibers.

Uniterms: Dogs; Heart; Myocardium; Connective tissue; Collagen. 


\section{SUMÁRIO}

1 INTRODUÇÃO 11

2 REVISÃO DA LITERATURA 18

2.1 Quanto ao tecido conjuntivo 19

2.2 Quanto as alterações teciduais cardiacas 22

3 MATERIAL E MÉTODO 27

4 RESULTADOS 30

4.1 Características Gerais 31

4.2 Proporção de Tecido Conjuntivo 31

$\begin{array}{ll}\text { 4.2.1 Ventrículo Esquerdo } & 31\end{array}$

4.2.1.1 face esquerda 31

4.2.1.1.1 porção proximal 31

4.2.1.1.2 porção média 32

4.2.1.1.3 porção distal 33

4.2.1.2 face direita 33

4.2.1.2.1 porção proximal 33

4.2.1.2.2 porção média 34

4.2.1.2.3 porção distal 35

4.2.2 Ventrículo Direito 35

4.2.2.1 face esquerda $\quad 35$

4.2.2.1.1 porção proximal 35

4.2.2.1.2 porção média 36

$\begin{array}{ll}\text { 4.2.2.1.3 porção distal } & 37\end{array}$ 


\subsubsection{2 face direita}

4.2.2.2.1 porção proximal

4.2.2.2.2 porção média

4.2.2.2.3 porção distal

4.2.3 Ápice

4.2.4 Septo Interventricular 40

4.3 Análise das Correlações

4.3.1 Correlação com o peso 40

$\begin{array}{ll}\text { 4.3.2 Correlação com a idade } & 41\end{array}$

4.3.3 Correlação com a altura ventricular 42

4.3.4 Correlação com a espessura ventricular 43

4.3.5 Correlação entre as porções 43

4.3.6 Correlação Face Esquerda X Face Direita nos ventrículos 44

4.3.7 Correlação Ventrículo Esquerdo x Ventrículo Direito 45

4.3.8 Correlação Ápice x Ventrículos 46

4.3.9 Correlação entre Septo Interventricular X Ventrículos 46

4.3.10 Correlação entre Septo Interventricular X Ápice 46

5 DISCUSSÃO 47

6 CONCLUSÃO $\quad 54$

7 REFERENNCIAS

$\begin{array}{lr}\text { TABELAS } & 59\end{array}$

$\begin{array}{ll}\text { ANEXOS } & 67\end{array}$ 


\section{INTRODUÇÃO}

Desde a Pré-história o coração tem sido um órgão de relevância, visto de diferentes maneiras pelo homem. Fonte de inspiração para alguns, motivo de estudo para outros - ou mesmo, quando considerado da forma mais simplória, como alvo nas caçadas, uma vez que indicava aos caçadores o ponto de maior vulnerabilidade - ou, ainda, mais filosoficamente, indicando o local onde os homens acreditavam residir a alma, o centro das emoções ou sentimentos, seja da forma que for abordado, ele nunca deixou de ser o centro das atenções e, ainda, muitos tem-se empenhado na busca da compreensão deste órgão.

Relatos bíblicos, de forma conotativa, demonstram o coração como sendo um centro responsável pela expressão da vontade, do pensamento e da ação. Dessa forma são Ihe atribuídas expressões tais como: sede de pensamentos e propósitos, capacidade de acusação, origem dos desígnios bons ou maus, local de meditação, mutabilidade, de onde procede a sinceridade e o engano.

Do Antigo Egito o "Tratado do Coração", inserido no chamado Papiro de Ebers, datado aproximadamente a 1550 a.C., adquirido por Georg Ebers em Tebas no inverno de 1872-73, cujo autor não é conhecido, apresentava uma análise do coração quanto ao seu papel central e diretor na distribuição de energia. Além de descrever a origem dos vasos que são distribuídos para todo o corpo; o autor dividia os vasos em 2 grupos: o do lado direito por onde fluía o 
"espírito da vida" e o do lado esquerdo, onde acreditava residir o "braço da morte"; textos que demonstram grande influência de superstição e misticismo. Os antigos egípcios tinham a esplêndida oportunidade de observar o interior do corpo devido ao seu costume de preservar os corpos dos seus mortos, necessitando a abertura da cavidade abdominal para tratamento especial das vísceras.

Em alguns relatos históricos de vários períodos da medicina antiga, fica evidente que muitas das grandes contribuições relativas ao coração foram baseadas em observações superficiais e elaboradas por muitas especulações errôneas. Estas observações e deduções primitivas, embora incompletas e enganadoras, foram, no obstante, muito importantes e, definitivamente, pavimentaram os pensamentos subseqüentes, análises e investigações e particularmente estimularam o desejo notável do saber e buscar a verdade naquela linha infinita da ciência.

Assim, podemos citar alguns cientistas que fizeram deste órgão notável objeto de seus estudos e dedicaram parte de suas vidas para compreendê-lo. Historicamente, encontramos Alcmaeon de Crotona ${ }^{1}$, uma antiga colônia grega, cerca de 500 a.C., que distinguiu veias de artérias e se acredita ter sido o primeiro praticante da dissecção anatômica. Anos mais tarde Hipócrates (460370 a.C.) descreveu válvulas cardíacas, os ventrículos do coração e os grandes vasos. Caminhando para a Grécia Antiga, Aristótoles (384-322 a.C.) foi o idealizador da comparação anatômica, nomeou a Aorta, apresentou uma grande descrição dos vasos superficiais e das veias em membros de

\footnotetext{
${ }^{1}$ WILLIUS e DRY (1948) - A HISTORY OF THE HEART AND THE CIRCULATION
} 
mamíferos e acreditava, ainda, que o número de ventrículos variava com o tamanho do animal. Já, Herófilo (335-280 a.C.) - o "pai da anatomia" - estudou este órgão meticulosamente com a apreciação dos movimentos de sístole e diástole e suas repercussões na rede vascular, o pulso. Entretanto foi com Cláudio Galeno de Pérgamo (138-201 d.C) que o estudo da relação coração e circulação teve seu grande impulso. Ele descreveu um fantástico conceito do coração e dos vasos sangüíneos; acreditava que o sangue era formado no fígado oriundo da alimentação, o sangue fluía do e para o fígado através das veias que consistiam da veia portal, a veia cava e uma bolsa ou divertículo do tórax ou ventrículo direito. Os átrios eram considerados somente saídas de segurança dos ventrículos. Galeno também aceitava a existência de um espírito vital, anima ou pneuma que era considerado o princípio essencial de vida e era obtido pelo ato de respirar. Este conceito, embora errôneo, foi universalmente aceito por aproximadamente 14 séculos.

Muito tempo depois, W. Harvey (1578-1657), através de um estudo sistemático e crítico intitulado "Exercitatio anatomica de motu cordis et sanguinis in animalibus", publicado em 1628, apresenta suas idéias sobre o coração e ainda refuta as idéias de Galeno. Escrito de maneira irônica, demonstrou a verdadeira natureza da anatomia e os princípios básicos da fisiologia do coração e da circulação, bem como, as doenças relativas a eles. Em sua declaração afirma:

“... que tudo o que até agora se afirmou sobre o movimento e as funções do coração e das artérias deve ser considerado incerto, obscuro e pleno de impossibilidade de qualquer consideração formal. Por isso será muito útil 
investigar as coisas um pouco mais a fundo e examinar cuidadosamente o movimento das artérias e do coração, não somente no homem mas também em todos os animais que têm coração, recorrendo freqüentemente às vivissecções e as observações com os próprios olhos, para investigar e se chegar à descoberta da verdade".

Ele apresentou o coração desprovido de contornos filosóficos, místicos, emotivos ou religiosos, contrariamente ao pensamento da época, analisando-o anatomicamente e tornando-o comprometido como o principal centro gerenciador da distribuição de nutrientes para as diversas partes do corpo e como órgão responsável pela manutenção dessa distribuição.

Neste mesmo século outras contribuições foram importantes, como a demonstração do sistema linfático, o ducto torácico e sua união com o sistema venoso, os eritrócitos foram descritos e visualizados pela primeira vez e a estrutura muscular do coração foi comprovada.

Na primeira metade do século 19, foram registradas muitas contribuições notáveis que dizem respeito ao coração. A introdução do estetoscópio e da auscultação por Laënnec, aliada aos conhecimentos de Corvisart sobre o método da percussão, revolucionaram profundamente esses estudos, completando os componentes para o diagnóstico físico moderno, ou seja, inspeção, palpação, percussão e auscultação, dando um grande passo no reconhecimento mais preciso das doenças do coração.

A classificação de novos sinais correlatos com sintomas de doenças e achados "pós-mortem" formaram a base para muitos conceitos modernos de doenças cardíacas, especialmente com referência aos defeitos valvulares, 
pericardite e a diferença entre hipertrofia e dilatação cardíaca. Nesta época, ainda, foram descobertos os nervos cardíacos e a ação inibitória do nervo Vago sobre o coração e já no final deste século, a descoberta dos Raios X cuja aplicação como método de auxílio no diagnóstico ampliou ainda mais os conhecimentos neste campo da medicina.

O início do século 20 foi marcado por muitas descobertas. As questões incertas começaram a ser respondidas ou clareadas e a cirurgia cardiovascular caminhava para tornar-se uma realidade. O desenvolvimento cardíaco era o principal acontecimento, onde Wilhelm His Jr. (1893), Franklin Mall (1912) e Julius Tandler (1914) descreveram com detalhes as modificações morfológicas básicas que transformam o tubo cardíaco primitivo em um coração com 4 cavidades.

Nas últimas décadas, a busca pela compreensão deste sistema tem sido empreendida de forma vigorosa, pois alguns aspectos funcionais e a forma como se relacionam as estruturas do coração, questões que ainda não estão por completo respondidas.

Estruturas como o músculo cardíaco, cuja forma e função são fundamentais para o trabalho adequado de todo o sistema cardiovascular, ganharam grande importância atualmente devido ao aumento das chamadas doenças cardíacas, que passaram a fazer parte do nosso cotidiano, uma vez que, qualquer modificação nesta estrutura pode ocasionar uma falha e comprometer outros sistemas e por conseguinte todo o organismo.

O remodelamento muscular cardíaco, como exemplo, é um processo que envolve muitos dos elementos que constituem normalmente o coração 
como um todo. Embora de natureza basicamente reversível, as mudanças adaptativas podem, por si, introduzir alterações secundárias que tornam o coração sujeito às lesões. A dilatação de uma câmara ventricular, por exemplo, seja aguda ou crônica, pode iniciar a disfunção do músculo papilar e, conseqüentemente, a insuficiência valvar. Esta situação produz um remodelamento dos ventrículos, como se pode evidenciar pelo aumento da câmara ventricular devido a uma carga aumentada de volume (BECKER, 1983).

Portanto, devemos ter em mente que, precisamos conhecer os mecanismos que envolvem o trabalho cardíaco, bem como todas as estruturas que participam deste. Para isto dispomos de diversas técnicas de estudo, uma delas é a morfometria.

Sob este prisma, podemos observar que a tendência dominante em diversas escolas anatômicas tem sido a de privilegiar os achados sistemáticos e, particularmente, os quantitativos, ao invés das descrições puramente observativas. Os aspectos quantitativos, base da morfometria, tem servido de pilar de sustentação para o embasamento conceitual da anatomia e, em especial, da anatomia funcional, uma vez que os dados métricos de alguma forma refletem a disposição funcional - como dizia Ruffini: "a forma (e dentro dela seus aspectos quantitativos - adendo nosso) é a imagem plástica da função." (DIDIO, 1974)

A metodologia de análise quantitativa de imagem tem servido como importante ferramenta da compilação de dados morfológicos, cujo 
desdobramento quase sempre se reflete na caracterização de conhecimentos aplicados.

As diferentes possibilidades do uso de inovações tecnológicas, tal como é a ferramenta que por nós foi utilizada, tem tornado possível a identificação de fenômenos, outrora relegados por conta da dificuldade no processamento, ora da amostra, ora da metodologia de contagem. Tais fenômenos tem adquirido credibilidade e confiabilidade científica na exata proporção da especificidade e acuidade dos novos aparelhos e softwares que são atualizados e desenvolvidos continuamente.

Eventos múltiplos e repetitivos em escala enésima podem agora ser quantificados com precisão em tempo racionalizado. Tal contribuição possibilitada pela utilização de ferramentas informatizadas podem de fato sustentar posições e informações, até então mantidas no plano da subjetividade e transformá-las em uma realidade concreta.

Nosso objetivo, portanto, será o de quantificar proporcionalmente o tecido conjuntivo e seus tipos existentes em determinada fração do tecido muscular de cães.

Os dados serão analisados mediante a aplicação de metodologia específica para análise de histo-imagens, com o uso de programas e equipamentos de leitura e processamento de dados. 


\section{REVISÃO DA LITERATURA}

O coração é o órgão muscular central do sistema circulatório que, por suas contrações rítmicas, atua como uma bomba de dupla sucção e de pressão e assim mantém o movimento do sangue dentro de um sistema fechado de tubos, os vasos sangüíneos. Embora um pouco variado de espécie para espécie, sua forma se assemelha a um cone. O coração e o pericárdio estão localizados no tórax, no espaço mediastínico que é limitado pelas pleuras do mediastino médio; são recobertos dorsalmente e lateralmente pelos pulmões. A parede do coração é constituída de três camadas, o epicárdio, o miocárdio e o endocárdio. O epicárdio é identificado como a lâmina visceral do pericárdio e forma uma membrana fina, transparente, recobrindo a superfície do coração; seu epitélio é cúbico cilíndrico e achatado, onde encontramos uma rede bem desenvolvida de fibras elásticas e uma densa camada de fibras colágenas. O miocárdio, uma parede muscular vermelha escura, consiste de células musculares que têm núcleos situados centralmente e são envolvidos por uma membrana, o sarcolema. O endocárdio constitui o revestimento endotelial liso do interior do coração e das valvas, é feito de células pavimentosas poliédricas com muitas fibras colágenas e poucas elásticas (GARDNER e GRAY e O'RAHILLY, 1971). A parede muscular ventricular é diferenciada em três camadas: uma subepicardial, uma média e uma subendocardial, possuindo fibras que correm entre uma camada e outra em um interlaçamento complexo (NICKEL, 1981). O coração é dividido internamente por uma curva transversalmente, por um septo longitudinal, limitado em um 
plano oblíquo, entre uma parte cranioventral (direita) e caudodorsal (esquerda). Aqueles onde são partes divididas transversalmente, chamadas câmaras de recepção, os átrios, e as bombas, os ventrículos (EVANS, 1993). A musculatura atrial é fina, enquanto que a musculatura ventricular é muito espessa e se dispõe em feixes superficiais e profundos. O ritmo inerente do coração é controlado por um marcapasso, um pequeno nó sinoatrial da musculatura modificada que forma o tecido condutor cardíaco e um segundo nó, o nó atrioventricular, este dá origem ao feixe atrioventricular (DYCE, 1987).

O rico suprimento sanguíneo do músculo cardíaco é considerável conforme o grande aporte de trabalho (NICKEL, 1981).

O coração também apresenta um esqueleto de tecido conjuntivo que sustenta e dá inserção a musculatura. A espessura da camada miocárdica é proporcional ao volume de trabalho que executa (GARDNER e GRAY e O’RAHILLY, 1971).

Muitos estudos há sobre a citologia dos corações de mamíferos, mas poucas informações estão avaliando os aspectos estruturais do espaço extracelular do miocárdio. A região entre a superfície celular miocárdica e o caminho dos capilares não tem sido estudada em detalhes nem tem suas estruturas sido quantificadas (FRANK e LANGER, 1974).

\subsection{Quanto ao tecido conjuntivo}

Tratados clássicos de morfologia indicam de maneira geral que alterações na quantidade, na arquitetura ou no arranjo do tecido conjuntivo do 
músculo cardíaco, principalmente de fibras colágenas, têm a característica de alterar o trabalho muscular cardíaco e, conseqüentemente, modificar a função cardíaca; bem como uma série de enfermidades, que podem comprometer os tecidos cardíacos, sejam musculares ou conjuntivos, também podem alterar a função cardíaca.

Assim JUNQUEIRA e CARNEIRO (1995) afirmam que o tecido conjuntivo caracteriza-se morfologicamente por apresentar diversos tipos de células separadas por abundante material intercelular, sintetizado por elas. Esse material é representado por uma parte com estrutura microscópica definida, as fibras do conjuntivo e por uma parte não estruturada, a substância fundamental amorfa. Os três tipos principais de fibras do conjuntivo são as colágenas, reticulares e elásticas, que se distribuem desigualmente entre as variedades de tecido conjuntivo, e as fibras predominantes muitas vezes são responsáveis por certas propriedades do tecido.

Segundo GANONG (1990), o tecido conjuntivo desempenha funções de sustentação, preenchimento, defesa e nutrição.

O tecido conjuntivo do músculo cardíaco é um componente importante responsável pelo mecanismo ventricular, contração e relaxamento. Morfologicamente há 3 tipos descritos de tecido conjuntivo em corações de mamíferos, conforme cita ROBINSON et al. (1983):

1) Epimisio: faixa de tecido conjuntivo ao redor de uma faixa muscular do coração.

2) Endomisio: pequena porção de tecido conjuntivo ao redor das células musculares do coração. 
3) Perimisio: faixa de tecido conjuntivo que une o endomisio ao epimisio e ao redor de grupos celulares do músculo cardíaco.

Estudos na matriz do tecido conjuntivo extracelular no coração têm mostrado uma complexa hierarquia organizacional (ROBINSON, 1983). A matriz intersticial de colágeno é um componente importante do miocárdio, que cerca e apóia os miócitos e a microcirculação coronária (BORG e CAUFIELD, 1981). Os tipos principais de colágeno presentes no interistício do miocárdio são I, III e V, sendo predominante o colágeno tipo I. O colágeno é a única uma proteína do organismo que mostra mudanças definidas conforme a idade, uma relação direta com o processo de envelhecimento (DEBESSA et al., 2001) e o aumento no conteúdo total de colágeno de certos tecidos tem sido encontrado com a idade (SOBEL e MARMORSTON, 1956; CLAUSEN, 1963). O fator responsável pelo aumento no conteúdo de fibras colágenas é, no momento, desconhecido.

CAULFIELD e BORG (1979) notaram que os miócitos estavam conectados aos miócitos adjacentes por um arranjo regular de fibras colágenas radiais de 120 a $150 \mathrm{~nm}$. Eles também relataram que um tecido conjuntivo trabalha rodeando grupos de 3 ou mais miócitos e que bandas adjacentes de miócitos foram encontradas soltas ou acopladas a relativamente esparsas e longas fibras de colágeno. Além disso é geralmente aceito que a matriz extracelular de tecido conjuntivo é um importante determinante da função cardíaca e que mudanças nessa rede podem levar a disfunção elétrica e mecânica no coração (ABRAHAMS, JANICHI e WEBER, 1987). 
FRANK e LANGER (1974) estudando o interstício do miocárdio de coelhos, através de microscopia eletrônica, descobriram que o espaço extracelular miocárdico possuía abundante substância amorfa $23 \%$, o restante do espaço continha $59 \%$ de vasos sangüíneos , $6 \%$ de espaço vazio, $4 \%$ de fibras colágenas e $7 \%$ de células do tecido conjuntivo.

Segundo WEBER (1989), o interstício do miocárdio inclui fibras do tecido conjuntivo, várias células - entre elas os fibroblastos e células plasmáticas - e uma substância composta de glicosaminoglicanos e glicoproteinas. Nervos cardíacos e vasos coronários também residem no interstício. Os miócitos representam aproximadamente um terço do número de células, entretanto seu volume ocupa dois terços do miocárdio. Colágenos tipo I e III são os componentes mais dominantes das fibras do tecido conjuntivo. As fibras elásticas são pouco vistas, mas presentes em largas quantidades nas artérias, promovendo a resistência necessária para a distensão dos vasos. O interstício possui muitas funções, entre elas incluímos: suporte dos miócitos cardíacos, artérias coronárias intramiocárdicas, arteríolas, capilares e veias; manter o mecanismo de defesa contra invasões por proteínas estranhas, bactérias e vírus; auxiliando a nutrição dos miócitos, por facilitar a troca de substâncias entre os miócitos e os capilares. 


\subsection{Quanto às alterações teciduais cardíacas}

Alterações no tecido conjuntivo do músculo cardíaco têm sido reportadas em várias condições patológicas que afetam a função do coração (WEBER, 1989; WEBER e BRILLA ,1991).

LUDOVICO (1998), ao estudar a hipertrofia ventricular esquerda e a regressão espontânea em ratos, admitiu que, do ponto de vista morfológico, podem ocorrer três condições na evolução da doença cardiovascular:

1. crescimento do estroma sem hipertrofia cardiocitária: a fibrose miocárdica induzida por irradiação e a vasculite coronária são exemplos de remodelação de células não miocitárias, nestas situações ocorre fibrose intersticial e perivascular sem hipertrofia cardiocitária;

2. Hipertrofia cardiocitária sem crescimento do estroma, encontrada em anemia crônica (BARTOSOVA et al., 1969), atletas (TOMANEK et al., 1972), portadores de fístulas arteriovenosas (MICHEL et al., 1986) e após administração de tiroxina ou hormônio do crescimento;

3. Crescimento concomitante de cardiócitos e de estroma, como ocorre na hipertensão arterial sistêmica, na estenose aórtica valvar e na coarctação da aorta. Nestas doenças, a hipertrofia ventricular esquerda caracteriza-se por crescimento das miocélulas acompanhado de acúmulo, proporcional ou desproporcional, de colágeno. 
MOORE et al (1980) sugeriu em seus estudos com 127 pacientes, oriundos do setor de autópsia do Hospital "Johns Hopkins" em Baltimore EUA, que a hipertrofia das células musculares cardíacas é geralmente acompanhada por aumento de tecido conjuntivo.

ROSSI (1998) num trabalho utilizando 12 corações, sendo 8 com miocardite chagásica crônica, por meio de microscopia eletrônica de varredura, observou que em grau variado, mas presente em todos os casos, havia uma fibrose difusa e intersticial em corações chagásicos. A mais impressionante característica observada foi um aumento difuso das fibras de colágeno rodeando bandas desorganizadas de músculos (perimísio) e ao redor dos vasos coronarianos intramiocárdicos, combinada com um aumento menos pronunciado de fibras colágenas do endomísio. Considerando que a fibrose é uma das mais proeminentes características da miocardite chagásica crônica, tanto em humanos como em animais experimentais, e que a matriz extracelular tem um importante papel na estrutura e função do miocárdio, a progressiva acumulação de colágeno intersticial pode bem ser o principal fator responsável pelo enfraquecimento progressivo da performance contrátil do miocárdio e pelo aumento do risco de arritmias em corações com Doença de Chagas crônica.

BADUI-DERGAL (1990), a partir de um estudo não-invasivo com 294 pacientes com diferentes doenças, notou que algumas enfermidades do tecido conjuntivo podem provocar inflamação e fibrose em qualquer uma das estruturas cardíacas: pericárdio, miocárdio, endocárdio, com complicações de intensidade variável. As enfermidades de tecido conjuntivo que mais afetam o coração são: Artrite reumatóide, Lupus eritematoso sistêmico, Espondilite 
anquilosante, Esclerose sistêmica progressiva, Dermatomiosite, Polimiosite, Enfermidade mista do tecido conjuntivo.

FEIN (1990), em estudos não-invasivos com humanos e experimentais com cães e ratos, observou que cães diabéticos têm um maior aumento na pressão diastólica final devido a um aumento no volume diastólico final se comparados com cães normais. Isto, acoplado com a bioquímica e histoquímica, evidenciou um aumento da glicoproteina e colágeno no interstício. Portanto, uma das maiores anormalidades cardíacas em diabéticos é o aumento intersticial de tecido conjuntivo. Como resultado final, observou-se uma diminuição das atividades ventriculares.

SANCHEZ-QUINTANA et al (1999), em estudos comparativos entre 6 corações de pacientes com Atresia de Tricúspide e 9 normais, utilizando microscopia eletrônica de varredura, observou que pacientes com Atresia de Tricúspide possuíam modificações no átrio direito e ventrículo esquerdo, além de apresentar diferenças na arquitetura muscular e na matriz do tecido conjuntivo em relação a corações normais. Presumiram que o aumento de tecido conjuntivo de corações malformados é primariamente causado por aumento de colágeno. Em estudo prévio, observaram um aumento nas fibras contidas em ambos os ventrículos, direito e esquerdo, em corações com Atresia de Tricúspide. Seu estudo mostrou que, em adição aqueles aumentos quantitativos, em relação ao tipo de conecção ventrículo-arterial, há mudanças morfológicas no arranjo dos tecidos conjuntivos intramiocárdicos, acompanhado de remodelagem da matriz colágena. A remodelagem na 
arquitetura pode certamente contribuir para o funcionamento anormal dos corações malformados.

DEBESSA et al. (2001) estudando o tecido muscular cardíaco de 12 corações e, em especial, as fibras de colágeno, demonstrou através da análise em microscopia de luz que há diferenças na quantidade e tipos de fibras de colágeno entre os corações de jovens e velhos. A perda de miócitos poderia ser uma causa da acumulação de colágeno, outro possível mecanismo para a acumulação de colágeno com a idade poderia ser uma inibição de degradação de colágeno (EGHBALI, 1990). Assim, o aumento do colágeno miocárdico pode contribuir para a diminuição da elasticidade ventricular com a idade (WERZÁR, 1969).

Além disso, pouco sabemos a respeito do papel da fina rede de tecido conjuntivo fibrilar que cerca as células musculares individuais do coração, formando um elemento tênsil que resiste à distensão e que fornece uma força restauradora, que pode produzir o retorno das células musculares individuais ao seu comprimento original depois da contração ( BECKER, 1983).

A literatura, pobre no sentido de discorrer sobre a inter-relação existente entre a morfologia do tecido muscular do coração e a quantidade de tecido conjuntivo, foi sem dúvida a nossa maior motivação para desenvolvermos esse projeto. Assim, no intuito de auxiliarmos no preenchimento de algumas lacunas existentes na literatura, decidimos realizar esse trabalho, fornecendo subsídios para que o clínico e/ou patologista possam avaliar o comprometimento cardíaco relacionado às alterações na quantidade de tecido conjuntivo do músculo cardíaco. 
3 MATERIAL E MÉTODO

Para desenvolvermos o presente trabalho utilizamos de corações de cães SRD, machos e fêmeas adultos, em igual número, sem histórico anterior de alteração cardíaca, confirmados através de exames eletrocardiográficos ecocardiográficos, cedidos e realizados pelo Hospital Veterinário da Faculdade de Medicina Veterinária e Zootecnia da Universidade de São Paulo (FMVZUSP). Desses animais coletamos dados gerais relativos à idade, raça, sexo, peso e causa mortis, que foram compilados em ficha protocolo.

Para o estudo histológico, os corações foram coletados mediante abertura lateral feita na cavidade torácica pelo lado esquerdo dos animais mediante incisão das costelas. Após retirada, os mesmos foram lavados e imediatamente medidos suas alturas, desde a emergência da artéria coronária esquerda a ponta do ápice, com auxílio de um paquímetro eletrônico digital marca Starrett $\circledast$. A partir da emergência da artéria Pulmonar, fez-se a abertura da cavidade ventricular direita e a partir da emergência da aorta, fez-se a abertura da cavidade ventricular esquerda. Logo após a abertura dos ventrículos, tomou-se a medida relativa a espessura da parede dos mesmos, tendo por base o terço médio da face esquerda de cada ventrículo. Retiramos fragmentos do terço proximal, médio e distal das faces esquerda e direita dos ventrículos direito e esquerdo e, posteriormente, estes foram subdivididos, ainda, em fragmentos representativos das camadas superficial e profunda da parede miocárdica; um fragmento do septo interventricular, padronizada a parte interna 
do ventrículo direito; um fragmento do ápice do coração, sendo, este, também, subdividido em fragmentos das camadas superficial e profunda.

Em seguida todos os fragmentos foram fixados em solução aquosa de formol a $10 \%$ para preparação segundo a técnica histológica convencional. Após tempo de 48 horas de fixação, o material foi processado segundo a seqüência convencional: desidratação, diafanização e inclusão em blocos de Paraplast ${ }$. Ao final obtivemos blocos contendo 1 segmento de cada um dos fragmentos de cada ventrículo, do septo interventricular e do ápice. Foram selecionadas 3 cortes com $5 \mu \mathrm{m}$ de cada bloco para confecção das lâminas, perfazendo um total de 390 lâminas. As lâminas foram coradas de acordo com as técnicas a seguir:

a) Picrosirius red, para evidenciação das fibras colágenas

b) Fucsina-Paraldeido e Tricromo de Gomori, para evidenciação das fibras elásticas, colágenas e demais componentes do tecido conjuntivo.

c) Hematoxilina-Eosina, para padronização e identificação do material.

As lâminas foram observadas com auxílio do microscópio óptico Axioscópio Zeiss ${ }^{\circ}$ e os resultados analisados em um microcomputador com programa de morfometria específico KS-400 Zeiss ${ }^{\circledR}$, segundo o seguinte processo:

1. Captação da imagem

2. Calibração do equipamento

3. Engenharia da imagem

i. identificação da freqüência da cor do tecido estudado por campo

ii. binarização da imagem 
4. Mensuração dos campos

5. Listagem dos dados

Padronizou-se a leitura e mensuração de 9 campos por lâmina, num total de 3.276 campos mensurados de 364 lâminas. De cada grupo de 9 mensurações foram retiradas médias que, multiplicadas segundo a espessura do corte padrão $(5 \mu \mathrm{m})$, foram agrupadas segundo a seqüência dos fragmentos. Para efeito de mensuração foram desprezadas as áreas de tecido conjuntivo referentes ao epícardio, endocárdio e margens das artérias ou veias (perivascular). Em seguida procedeu-se a análise e discussão dos resultados. Também realizamos fotomicrografias para documentação.

Posteriormente, os resultados obtidos foram agrupados segundo a idade e sexo para comparação dos parâmetros entre as variáveis. Os dados adquiridos foram tratados estatisticamente em programas compatíveis com ambiente Windows. Também utilizamos o teste de Correlação de Pearson para correlacionar as diferentes variáveis. 


\section{RESULTADOS}

Para a descrição dos resultados valemo-nos da leitura de 9 campos ópticos obtidos de cortes histológicos corados mediante 2 técnicas diferentes; sendo que apenas para a verificação e tratamento estatístico optamos pela utilização dos valores oriundos da técnica de coloração que apresentasse o menor desvio padrão. Os valores assinalados correspondem a média individual para cada animal de todas as leituras realizadas. Assim, procedemos a indicação dos resultados dividindo os achados segundo a topografia, face, porção e camada.

È importante frisarmos que o tecido conjuntivo, nas diversas porções por nós analisadas, apresentou-se de maneira diversificada. Encontramos quantidade variável de tecido conjuntivo envolvendo as artérias coronárias e as camadas do endocárdio e epicárdio e distintamente quantidade de tecido conjuntivo menor do que a primeira referida envolvendo os miócitos. Também esta quantidade de tecido conjuntivo variava conforme a porção observada. As fibras que predominantes eram do tipo colagênicas, já as fibras elásticas restringiam-se as regiões de vasos, epicárdio e endocárdio.

- Apresentação dos Resultados 


\subsection{Características Gerais}

Dos animais utilizados, em relação ao sexo, buscamos a sua paridade, portanto trabalhamos o mesmo número de machos e fêmeas. Já, concernente a idade, esta ficou compreendida entre 48 e 150 meses em animais pesando entre 18,6 e $30 \mathrm{Kg}$.

Quanto a Altura Ventricular e Espessura dos Ventrículos: a altura ventricular (AV) variou de 7,3 a $11,2 \mathrm{~cm}$, com média de $8,9 \mathrm{~cm}$. A espessura dos ventrículos (EV) variou de 0,3 a 0,6 cm, com média de $0,4 \mathrm{~cm}$ e de 0,8 a 1,4 cm, com média de $11,3 \mathrm{~cm}$, respectivamente para os ventrículos direito e esquerdo.

4.2 Proporção de tecido conjuntivo

\subsubsection{Ventrículo Esquerdo (VE)}

\subsubsection{Face Esquerda}

\subsection{Porção Proximal}

Na porção proximal encontramos variação entre 1,74\% e 10,83\% de tecido conjuntivo, dispostos entre as fibras musculares da camada superficial, segundo a técnica de coloração FPG, com média de 5,67\%, mediana de $4,38 \%$ e desvio padrão de $\pm 3,98$; já em relação a técnica de coloração $P R$, notamos valores variando de $4,52 \%$ a $16,11 \%$, com média de $11,13 \%$, mediana de $10,21 \%$ e desvio padrão de $\pm 7,99$. 
Para a mesma porção, agora em relação a camada profunda, encontramos valores variando entre $1,78 \%$ e $7,59 \%$ de tecido conjuntivo entre as fibras musculares, segundo a técnica FPG, com média de 5,29\%, mediana de 5,90\% e desvio padrão de $\pm 2,30$; já em relação a técnica de coloração $P R$, encontramos variação de $1,63 \%$ a $11,72 \%$, com média de $5,38 \%$, mediana de $5,25 \%$ e desvio padrão de $\pm 3,58$.

\subsection{Porção Média}

Na porção média encontramos variação entre $1,43 \%$ e $11,40 \%$ de tecido conjuntivo, dispostos entre as fibras musculares da camada superficial, segundo a técnica de coloração FPG, com média de 4,06\%, mediana de 2,80\% e desvio padrão de $\pm 3,82$; já em relação a técnica de coloração $P R$, notamos valores variando de 2,85\% a 15,00\%, com média de $8,75 \%$, mediana de $8,44 \%$ e desvio padrão de $\pm 5,01$.

Para a mesma porção, agora em relação a camada profunda, encontramos valores variando entre $2,10 \%$ e $19,69 \%$ de tecido conjuntivo entre as fibras musculares, segundo a técnica FPG, com média de 7,41\%, mediana de 5,61\% e desvio padrão de $\pm 6,60$; já em relação a técnica de coloração $P R$, encontramos variação de 2,60\% a 14,74\%, com média de $8,68 \%$, mediana de $8,10 \%$ e desvio padrão de $\pm 4,69$. 


\subsection{Porção Distal}

$\mathrm{Na}$ porção distal encontramos variação entre $2,06 \%$ e $17,23 \%$ de tecido conjuntivo, dispostos entre as fibras musculares da camada superficial, segundo a técnica de coloração FPG, com média de $7,70 \%$, mediana de $6,62 \%$ e desvio padrão de $\pm 5,10$; já em relação a técnica de coloração $P R$, notamos valores variando de $1,95 \%$ a $20,41 \%$, com média de $13,88 \%$, mediana de $15,46 \%$ e desvio padrão de $\pm 6,25$.

Para a mesma porção, agora em relação a camada profunda, encontramos valores variando entre $0,44 \%$ e $10,28 \%$ de tecido conjuntivo entre as fibras musculares, segundo a técnica FPG, com média de 4,88\%, mediana de 5,33\% e desvio padrão de $\pm 3,91$; já em relação a técnica de coloração $P R$, encontramos variação de $1,33 \%$ a $14,28 \%$, com média de $6,05 \%$, mediana de 5,95\% e desvio padrão de $\pm 4,70$.

\subsubsection{Face Direita}

\subsection{Porção Proximal}

Na porção proximal encontramos variação entre $2,31 \%$ e $14,03 \%$ de tecido conjuntivo, dispostos entre as fibras musculares da camada superficial, segundo a técnica de coloração FPG, com média de $8,17 \%$, mediana de $7,54 \%$ e desvio padrão de $\pm 4,60$; já em relação a técnica de coloração $P R$, notamos valores variando de $3,23 \%$ a $18,64 \%$, com média de $9,45 \%$, mediana de $7,64 \%$ e desvio padrão de $\pm 6,37$. 
Para a mesma porção, agora em relação a camada profunda, encontramos valores variando entre $2,49 \%$ e $11,51 \%$ de tecido conjuntivo entre as fibras musculares, segundo a técnica FPG, com média de 5,98\%, mediana de 4,50\% e desvio padrão de $\pm 4,02$; já em relação a técnica de coloração $P R$, encontramos variação de $4,03 \%$ a $14,82 \%$, com média de $8,92 \%$, mediana de $8,20 \%$ e desvio padrão de $\pm 5,45$.

\subsection{Porção Média}

Na porção média encontramos variação entre $2,31 \%$ e $11,66 \%$ de tecido conjuntivo, dispostos entre as fibras musculares da camada superficial, segundo a técnica de coloração FPG, média de $7,63 \%$, mediana de $7,71 \%$ e desvio padrão de $\pm 3,46$; já em relação a técnica de coloração $P R$, notamos valores variando de $2,21 \%$ a $18,96 \%$, com média de $11,90 \%$, mediana de $14,18 \%$ e desvio padrão de $\pm 6,19$.

Para a mesma porção, agora em relação a camada profunda, encontramos valores variando entre $3,74 \%$ e $10,16 \%$ de tecido conjuntivo entre as fibras musculares, segundo a técnica FPG, com média de 6,47\%, mediana de 7,20\% e desvio padrão de $\pm 3,04$; já em relação a técnica de coloração $P R$, encontramos variação de $2,90 \%$ a 24,71\%, com média de 10,52\%, mediana de 10,11\% e desvio padrão de $\pm 8,49$. 


\subsection{Porção Distal}

$\mathrm{Na}$ porção distal encontramos variação entre $2,46 \%$ e $16,39 \%$ de tecido conjuntivo, dispostos entre as fibras musculares da camada superficial, segundo a técnica de coloração FPG, com média de $8,25 \%$, mediana de $8,41 \%$ e desvio padrão de $\pm 5,12$; já em relação a técnica de coloração $P R$, notamos valores variando de $4,97 \%$ a $26,26 \%$, com média de $12,66 \%$, mediana de $11,41 \%$ e desvio padrão de $\pm 7,66$.

Para a mesma porção, agora em relação a camada profunda, encontramos valores variando entre $2,70 \%$ e $9,62 \%$ de tecido conjuntivo entre as fibras musculares, segundo a técnica FPG, com média de 5,10\%, mediana de 4,30\% e desvio padrão de $\pm 2,13$; já em relação a técnica de coloração $P R$, encontramos variação de $2,35 \%$ a $14,34 \%$, com média de $6,76 \%$, mediana de $5,10 \%$ e desvio padrão de $\pm 4,71$.

\subsubsection{Ventrículo Direito (VD)}

\subsubsection{Face Esquerda}

\subsection{Porção Proximal}

Na porção proximal encontramos variação entre 4,03\% e 13,82\% de tecido conjuntivo, dispostos entre as fibras musculares da camada superficial, segundo a técnica de coloração FPG, com média de 10,38\%, mediana de 11,39\% e desvio padrão de $\pm 4,01$; já em relação a técnica de coloração $P R$, notamos valores 
variando de $3,26 \%$ a $17,11 \%$, com média de $11,30 \%$, mediana de $12,98 \%$ e desvio padrão de $\pm 5,98$.

Para a mesma porção, agora em relação a camada profunda, encontramos valores variando entre $2,84 \%$ e $17,91 \%$ de tecido conjuntivo entre as fibras musculares, segundo a técnica FPG, com média de 7,08\%, mediana de 5,37\% e desvio padrão de $\pm 5,50$; já em relação a técnica de coloração $P R$, encontramos variação de $2,25 \%$ a $21,18 \%$, com média de $11,27 \%$, mediana de $11,05 \%$ e desvio padrão de $\pm 8,13$.

\subsection{Porção Média}

Na porção média encontramos variação entre $7,30 \%$ e $15,17 \%$ de tecido conjuntivo, dispostos entre as fibras musculares da camada superficial, segundo a técnica de coloração FPG, com média de 10,45\%, mediana de 10,71\% e desvio padrão de $\pm 2,93$; já em relação a técnica de coloração $P R$, notamos valores variando de $4,14 \%$ a $14,03 \%$, com média de $9,50 \%$, mediana de $10,66 \%$ e desvio padrão de $\pm 4,37$.

Para a mesma porção, agora em relação a camada profunda, encontramos valores variando entre $2,51 \%$ e $11,76 \%$ de tecido conjuntivo entre as fibras musculares, segundo a técnica FPG, com média de 7,44\%, mediana de 7,63\% e desvio padrão de $\pm 3,83$; já em relação a técnica de coloração $P R$, encontramos variação de $6,16 \%$ a $17,45 \%$, com média de $11,10 \%$, mediana de $9,85 \%$ e desvio padrão de $\pm 4,14$. 


\subsection{Porção Distal}

$\mathrm{Na}$ porção distal encontramos variação entre $2,46 \%$ e $18,85 \%$ de tecido conjuntivo, dispostos entre as fibras musculares da camada superficial, segundo a técnica de coloração FPG, com média de $11,71 \%$, mediana de $12,22 \%$ e desvio padrão de $\pm 5,99$; já em relação a técnica de coloração $P R$, notamos valores variando de $3,86 \%$ a $20,78 \%$, com média de $10,22 \%$, mediana de $9,00 \%$ e desvio padrão de $\pm 6,84$.

Para a mesma porção, agora em relação a camada profunda, encontramos valores variando entre $1,75 \%$ e $6,17 \%$ de tecido conjuntivo entre as fibras musculares, segundo a técnica FPG, com média de 3,37\%, mediana de 3,13\% e desvio padrão de $\pm 1,60$; já em relação a técnica de coloração $P R$, encontramos variação de $1,77 \%$ a 10,52\%, com média de $4,20 \%$, mediana de $3,03 \%$ e desvio padrão de $\pm 3,21$.

\subsubsection{Face Direita}

\subsection{Porção Proximal}

Na porção proximal encontramos variação entre $2,81 \%$ e $13,28 \%$ de tecido conjuntivo, dispostos entre as fibras musculares da camada superficial, segundo a técnica de coloração FPG, com média de 7,27\%, mediana de 7,68\% e desvio padrão de $\pm 3,90$; já em relação a técnica de coloração $P R$, notamos valores variando de $4,15 \%$ a $15,68 \%$, com média de $8,26 \%$, mediana de $6,81 \%$ e desvio padrão de $\pm 4,50$. 
Para a mesma porção, agora em relação a camada profunda, encontramos valores variando entre $3,33 \%$ e $14,61 \%$ de tecido conjuntivo entre as fibras musculares, segundo a técnica FPG, com média de 7,64\%, mediana de 7,19\% e desvio padrão de $\pm 4,11$; já em relação a técnica de coloração $P R$, encontramos variação de $3,92 \%$ a 16,75\%, com média de $10,32 \%$, mediana de $10,83 \%$ e desvio padrão de $\pm 5,11$.

\subsection{Porção Média}

Na porção média encontramos variação entre $1,26 \%$ e $18,44 \%$ de tecido conjuntivo, dispostos entre as fibras musculares da camada superficial, segundo a técnica de coloração FPG, com média de 9,20\%, mediana de 9,41\% e desvio padrão de $\pm 6,31$; já em relação a técnica de coloração $P R$, notamos valores variando de 3,91\% a 18,09\%, com média de $9,30 \%$, mediana de $8,37 \%$ e desvio padrão de $\pm 5,03$.

Para a mesma porção, agora em relação a camada profunda, encontramos valores variando entre $1,23 \%$ e $7,24 \%$ de tecido conjuntivo entre as fibras musculares, segundo a técnica FPG, com média de 2,55\%, mediana de 1,71\% e desvio padrão de $\pm 2,32$; já em relação a técnica de coloração $P R$, encontramos variação de $1,32 \%$ a 9,16\%, com média de 4,74\%, mediana de 4,08\% e desvio padrão de $\pm 3,05$. 


\subsection{Porção Distal}

$\mathrm{Na}$ porção distal encontramos variação entre $2,13 \%$ e $13,76 \%$ de tecido conjuntivo, dispostos entre as fibras musculares da camada superficial, segundo a técnica de coloração FPG, com média de 8,43\%, mediana de 9,76\% e desvio padrão de $\pm 4,95$; já em relação a técnica de coloração $P R$, notamos valores variando de $4,62 \%$ a $18,12 \%$, com média de $11,47 \%$, mediana de $12,30 \%$ e desvio padrão de $\pm 5,06$.

Para a mesma porção, agora em relação a camada profunda, encontramos valores variando entre $0,97 \%$ e $11,60 \%$ de tecido conjuntivo entre as fibras musculares, segundo a técnica FPG, com média de 5,45\%, mediana de 4,01\% e desvio padrão de $\pm 4,30$; já em relação a técnica de coloração $P R$, encontramos variação de 2,92\% a 13,07\%, com média de 6,68\%, mediana de 6,05\% e desvio padrão de $\pm 3,45$.

\subsection{3 Ápice}

Encontramos variação na camada superficial entre 1,32\% e 13,40\% de tecido conjuntivo presente entre as fibras musculares segundo a técnica FPG, com média de $5,87 \%$, mediana de $4,68 \%$ e desvio padrão de $\pm 4,21$; já segundo a técnica PR, encontramos variação entre $1,35 \%$ e $29,24 \%$, com média de $9,45 \%$, mediana de $5,22 \%$ e desvio padrão de $\pm 10,41$.

Para a mesma porção, mas na camada profunda os valores variaram entre $1,32 \%$ e $9,12 \%$ de tecido conjuntivo entre as fibras musculares, segundo a técnica 
FPG, com média de 4,43\%, mediana de $4,52 \%$ e desvio padrão de $\pm 2,85$; enquanto que a camada profunda apresentou variação de $3,20 \%$ a $14,63 \%$, segundo a técnica PR, com média de 10,10\%, mediana de $12,21 \%$ e desvio padrão de $\pm 5,18$.

\subsubsection{Septo Interventricular}

Encontramos variação entre $6,76 \%$ e $11,24 \%$ de tecido conjuntivo presente entre as fibras musculares, segundo a técnica FPG, com média de 8,62\%, mediana de $8,16 \%$ e desvio padrão de $\pm 1,62$; já segundo a técnica de $P R$ encontramos os valores variando entre $5,41 \%$ e $9,60 \%$, com média de $7,57 \%$, mediana de $7,49 \%$ e desvio padrão de $\pm 1,73$.

\subsection{Análise das Correlações}

\subsubsection{Correlação com o peso do animal (Tab. 1 e Tab. 2)}

Em relação aos ventrículos: a correlação entre peso e a quantidade de tecido conjuntivo em cada uma das porções ventriculares, tanto a esquerda como a direita, considerando as duas colorações, se faz de maneira aleatória, não permitindo afirmar que existe correlação entre esses dois fatores.

Em relação ao ápice: a correlação entre peso dos animais e a quantidade de tecido conjuntivo em cada uma das porções do ápice, tanto superficial como 
profunda, considerando a coloração FPG, se apresentaram positiva de intensidade média, enquanto que, segundo a coloração $P R$, se apresentou positiva de intensidade baixa na camada superficial, mas a camada profunda apresentou correlação negativa de intensidade média; isto nos leva a acreditar que alterações no peso do animal promovem alteração da quantidade de tecido conjuntivo presente no ápice do coração de cães.

Em relação ao septo interventricular: a correlação entre peso e septo interventricular, considerando as duas colorações, apresentou correlação negativa de média intensidade, evidenciando que, um aumento do peso dos animais influencia na quantidade de tecido conjuntivo presente no septo interventricular.

\subsubsection{Correlação com a Idade (Tab. 3 e Tab. 4)}

Em relação aos ventrículos: a correlação entre peso e a quantidade de tecido conjuntivo em cada uma das porções ventriculares, tanto a esquerda como a direita, considerando as duas colorações, se faz de maneira aleatória, não permitindo afirmar que existe correlação entre esses dois fatores.

Em relação ao ápice: encontramos correlação positiva de média intensidade na camada profunda, segundo a técnica de PR; correlação positiva de baixa intensidade na camada superficial, segundo a técnica de FPG e correlação nula para a camada profunda, segundo a mesma técnica; desta forma podemos acreditar que animais com maior idade tendem a apresentar maior quantidade de tecido conjuntivo presente no ápice. 
Em relação ao septo interventricular: encontramos correlação positiva de média intensidade entre a idade e a quantidade de tecido conjuntivo presente no septo interventricular, também nos levando a acreditar que animais com maior idade, devem possuir maior quantidade de tecido conjuntivo presente na parede septal.

\subsubsection{Correlação da Altura Ventricular (Tab. 5 e Tab. 6)}

Em relação aos ventrículos: a correlação entre altura ventricular e a quantidade de tecido conjuntivo em cada uma das porções ventriculares, tanto a esquerda como a direita, considerando as duas colorações, se faz de maneira aleatória, não permitindo afirmar que existe correlação entre esses dois fatores. Com exceção da porção proximal da face esquerda do VE, que apresentou uma correlação negativa de média intensidade entre altura ventricular e quantidade de tecido conjuntivo.

Em relação ao ápice: encontramos correlações negativas variáveis entre esses dois fatores, se apresentando de média intensidade na camada proximal, nas duas colorações; de alta e baixa intensidade na camada profunda, segundo a coloração FPG e PR, respectivamente.

Em relação ao septo interventricular: encontramos uma correlação positiva de média intensidade, segundo a coloração FPG e correlação nula, segundo a técnica PR, entre a altura ventricular e a quantidade de tecido conjuntivo presente parede septal. 
4.3.4 Correlação da Espessura Ventricular (Tab. 7, Tab. 8 e Tab. 9)

Em relação aos ventrículos: encontramos também correlações de valores variáveis, aleatórios, portanto não podemos afirmar que existe uma correlação clara entre esses dois fatores, em ambas as colorações, independente das porções analisadas.

Em relação ao ápice: apresentou-se correlação negativa de baixa e média intensidade em relação a espessura do VD, mas apresentou correlação variável, nula ou positiva, em relação ao VE.

Em relação ao septo interventricular: apresentou correlação positiva de média intensidade para a coloração FPG e de baixa intensidade para a coloração PR, tanto em relação ao VE, quanto ao VD, nos levando a acreditar que alterações na espessura da parede dos ventrículos afetam a quantidade de tecido conjuntivo da parede septal.

\subsubsection{Correlação entre as Porções}

\subsubsection{Correlação Porção Proximal X Porção Média nos Ventrículos (Tab. 11)}

Em relação as porções proximais correlacionadas com as porções médias, tanto do VE quanto do VD, não encontramos correlações claras, entre as duas porções, devido aos valores se apresentarem de forma aleatória, não dando margem a interpretações em relação a possíveis alterações na quantidade de tecido conjuntivo. 
4.3.5.2 Correlação entre a Porção Proximal X Porção Distal (Tab. 11)

Em relação as porções proximais correlacionadas com as porções distais, tanto do VE quanto do VD, também não foram encontradas correlações claras entre as duas porções, portanto os valore se apresentaram aleatórios não dando margem a interpretações em relação as alterações na quantidade de teciodo conjuntivo.

\subsubsection{Correlação entre a Porção Média X Porção Distal (Tab. 11)}

Em relação as porções médias correlacionadas com as porções distais, tanto do VE quanto do direito, não foram encontradas correlações claras entre elas, possuindo valores não uniformes e aleatórios, não dando margem a possíveis interpretações em relação as alterações na quantidade de tecido conjuntivo.

\subsubsection{Correlação Face Esquerda X Face Direita nos Ventrículos (Tab. 12)}

Em relação a correlação entre as faces direita e esquerda, do mesmo ventrículo, não foram encontrados valores que mostrassem qualquer correlação existente entre as mesmas que pudessem afirmar inter-relações ente elas, devido aos valores se apresentaram de forma aleatória e não uniforme. 
4.3.7 Correlação Ventrículo Esquerdo X Ventrículo Direito (Tab. 10)

A) Encontramos correlação positiva de alta intensidade entre as faces esquerdas, porção proximal, camada superficial, nas duas colorações e entre as faces direitas, porção média, camada profunda, segundo a técnica PR.

B) Encontramos correlação positiva de média intensidade entre a faces esquerdas, porção proximal, camada profunda, segundo a técnica PR; entre as faces direitas, porção média superficial, segundo a técnica PR e média profunda segundo a técnica FPG.

C) Encontramos correlação positiva de baixa intensidade entre as faces esquerdas, porção média, camada superficial, segundo a técnica FPG e porção distal, camada profunda, segundo a técnica PR; entre as faces direitas, porção média superficial, segundo a técnica PR e porção distal superficial, segundo a técnica FPG.

D) Encontramos correlação negativa de alta intensidade somente entre as faces direitas, porção proximal, camada profunda, segundo a técnica PR

E) Encontramos correlação negativa de média intensidade somente entre as faces esquerdas, porção distal superficial, segundo a técnica FPG.

F) Encontramos correlação negativa de baixa intensidade somente entre as faces esquerdas, porção média, camada superficial, segundo a técnica PR e porção distal superficial, segundo a mesma técnica.

G) Encontramos correlação nula entre as faces esquerdas, porção distal, camada profunda, segundo a técnica FPG; entre as faces direitas, porção distal, camada superficial e profunda, segundo a técnica PR. 


\subsubsection{Correlação Ápice X Ventrículos (Tab. 13)}

Em relação a correlação ápice e ventrículos encontramos correlação que apresentaram valores variáveis, tanto positivos, quanto negativos e nulos, aleatórios e não uniformes, impedindo que se façam quaisquer interpretações entre as alterações na quantidade de tecido conjuntivo.

\subsubsection{Correlação entre Septo Interventricular X Ventrículos (Tab. 14)}

Encontramos correlação positiva de intensidade média somente para as porções médias, camada superficial, de ambas as faces e de ambos os ventrículos. Encontramos correlação negativa de baixa intensidade na porção média, camada superficial, da face esquerda do ventrículo direito. Nas demais porções encontramos valores variados, não uniformes, não podendo identificar uma correlação direta entre septo interventricular e ventrículos.

\subsubsection{Correlação entre Septo Interventricular e Ápice (Tab. 15)}

Podemos encontrar correlações positivas de intensidade baixa, na camada superficial, segundo as duas colorações; de intensidade alta na camada profunda, segundo a técnica PR e correlação negativa de baixa intensidade na camada profunda, segundo a técnica FPG. 


\section{DISCUSSÃO}

Os trabalhos quantitativos são importantes pois oferecem precisão e acurácia no estabelecimento de conceitos ou no subsidiamento de conhecimentos morfológicos.

Nossas observações de ordem genérica são concordantes com aquelas existentes nos tratados clássicos como os descritos por NICKEL (1981); EVANS (1993); DYCE (1987); FRANK E LANGER (1974); JUNQUEIRA e CARNEIRO (1995), no entanto vale ressaltar que as referidas citações contém informações de ordem descritiva, ora das estruturas em estudo, ora do órgão como um todo, e mesmo da importância funcional do tecido conjuntivo, mas, em nenhum momento, fazem menção a aspectos quantitativos, tais como os por nós estudados, até porque tais referências são tratados clássicos que pela sua formatação não possuem caráter sistemático.

Segundo ROBINSON et al. (1983) o tecido conjuntivo do músculo cardíaco está constituido por componentes que variam grandemente em tamanho e forma. A diversidade destas estruturas, indubitavelmente, refletem um considerável requerimento dinâmico do coração, como por exemplo, sua resistência as dramáticas mudanças de sua forma durante o ciclo cardíaco. Também concordamos com esta afirmação por encontrarmos uma considerável variação na proporção de componentes conjuntivos das diversas porções do músculo cardíaco de cães, no entanto seus reflexos na dinâmica 
circulatória não possuem embasamento sistemático, tornando-se apenas ponderações e/ou sugestões.

SANCHES-QUINTANA et al. (1999) concluiram que o colágeno é o maior componente da matriz do tecido conjuntivo intramiocárdico, observando, ainda, aumento de colágeno e remodelação na matriz do tecido conjuntivo em corações anormais. Em nosso material podemos observar que a predominância de tecido conjuntivo presente nas porções miocárdicas estudadas eram formadas por colágeno e que as fibras elásticas estavam presentes nas regiões de epicárdio, endocárdio, camadas íntima e média dos grandes vasos; e, que, devido a sua quantidade e localização, não puderam ser quantificadas, pois essas áreas foram previamente descartadas para efeito de quantificação, entretanto ainda que o trabalho de SANCHES-QUINTANA et al. não tenha o caráter métrico, suas afirmações possuem correspondência com nossos achados.

Segundo DOERR (1959) apud BARGMANN (1968), o tecido intersticial do miocárdio não está igualmente desenvolvido em todas as partes. A parede do ventrículo direito cujas fibras musculares são mais delgadas que a do esquerdo, tendo por outro lado mais interstício que este. Tal circunstância é importante para compreensão da localização de alguns processos nozológicos do miocárdio. Os processos inflamatórios e o edema se estendem com mais facilidade naqueles pontos onde o interstício conjuntivo é mais desenvolvido e, também, os produtos do metabolismo se depositam preferencialmente nestes locais. Com relação a este fato, encontramos em nosso trabalho resultados que concordam com a citação do autor, ainda que aquele não tenha se 
prendido as observações quantitativas, valendo-se de amostras e observações subjetivas para tal afirmação; de fato o ventrículo direito apresentou maior quantidade de tecido conjuntivo do que o esquerdo, se comparado os valores médios de cada porção; parece-nos que processos intersticiais ocorrem predominantemente onde o tecido intersticial é mais desenvolvido, por conta da sua disposição e características hidrófilas, no entanto, ressaltamos que tal fato não foi objetivo de nossa exploração, ainda que, subjetivamente constatado.

De forma geral, WEBER (1989); WEBER e BRILLA (1991); WEBER et al. (1991) afirmam que o volume fracional de colágeno miocárdico é pequeno; sendo que o volume ocupado pelos miócitos é cerca de $2 / 3$ do miocárdio e o tecido intersticial ocupa $1 / 3$ do miocárdio; colágeno tipo I e III são os componentes mais dominantes do tecido conjuntivo intersticial, as fibras elásticas são pouco vistas, mas presentes em largas quantidades nas artérias; a concentração de colágeno no Ventrículo Direito 30\% maior que no Esquerdo, devido ao menor tamanho dos miócitos (CASPARI, 1976 - apud WEBER,1991); essas afirmações coadunam-se com os nossos resultados, onde a presença de maior quantidade de colágeno foi evidenciada para o ventrículo direito, se comparados os valores médios de cada porção, ainda que, para os valores mínimos e máximos encontramos maior variação na quantidade de tecido conjuntivo referente ao ventrículo esquerdo, de $0,44 \%$ a $26,26 \%$ enquanto que o ventrículo direito apresentou variação entre $0,97 \%$ e $21,18 \%$. Também concordamos nas afirmações de que o tecido predominante do miocárdio é o muscular e que a fração de tecido conjuntivo é pequena, isto se torna mais claro a medida que entendemos as funções dos tecidos cardíacos. 
ROBINSON et. al (1983) caracterizou os componentes do tecido conjuntivo cardiaco e a sua distribuição em várias regiões, encontrando variação de 10 a $70 \mathrm{~nm}$ no diâmetro das fibras de colágeno, mas não determinou a quantidade de fibras éxistentes nessas regiões. Também CAUFIELD e BORG (1979), se preocuparam em mensurar o diâmetro das fibras, sem quantificá-las, encontrando em corações hipertrofiados fibras colágenas com diâmetros que variavam de 250 a $300 \mathrm{~nm}$. Ainda que não tenhamos nos detido na medida do diâmetro das fibras, nossas observações, sugerem nos cães, valores próximos daquelas relatadas para o homem e acreditamos que há uma inter-relação direta entre a hipertrofia do coração e o aumento no diâmetro das fibras de colágeno, fato este que tem sido objeto de pesquisa paralela e programada por nós.

FRANK e LANGER (1974), estudando o interstício do miocárdio de coelhos, relatam que esse espaço possuía $4 \%$ de fibras colágenas. Ao analisar a quantidade, a solubilidade e a composição de colágeno intramuscular do ventrículo esquerdo de vários mamíferos, usando a determinação do conteúdo de hidroxiprolina, MEDUGORAC (1982) descobriu que o tecido do ventrículo esquerdo do rato contém normalmente $2,2 \%$ de colágeno, entretanto o porco e coelho apresentaram 3,2\% e, ainda, o gato, a vaca e o cão 3,8\%; com 55 a $90 \%$ do total de colágeno extraído, através da digestão moderada com pepsina a $0,1 \%$. Concluiu que o conteúdo de colágeno miocárdico pode ser substancialmente alterado em certas doenças miocárdicas, entretanto não observou alterações na distribuição desse componente, mas acredita que 
alterações na distribuição ou relação dos tipos de colágeno podem afetar as propriedades mecânicas do músculo cardiaco.

Segundo o autor cerca de $88 \%$ do total de colágeno do ventrículo esquerdo do coração de cão foi extraído, se analisarmos esta proporção e compararmos aos nossos dados veremos que encontraremos semelhanças entre eles; também concordamos que alterações na quantidade ou distribuição das fibras de colágeno podem afetar a função cardíaca.

Nossos achados são concordantes com aquele relatado para cães, ainda que os valores citados mantenham certas divergências com os nossos valores absolutos; assim cremos que tais divergências possam estar sendo decorrentes da estratégia metodológica diferente daquela por nós adotada; pode-se dizer que o autor valeu-se da extração do tecido conjuntivo pela técnica da pepsina, ou ainda, do fato de que ele não diferencia o tecido intersticial do endocárdio, epicárdio e perivascular do tecido intersticial do miocárdio.

ROSSI (1998) encontrou alterações na matriz do perimísio do tecido conjuntivo de corações com miocardite crônica chagásica, concluindo que a distribuição de colágeno pode interferir com as propriedades elétricas do miocárdio, interferindo com a condução do impulso. De igual forma LeGRICE et al. (1995) concluiu que a matriz extracelular de tecido conjuntivo é um importante determinante da função cardiaca e que alterações na sua rede podem levar a disfunção elétrica e mecânica do coração; ainda que não afirmem claramente esta alteração é decorrente da variação na quantidade de tecido conjuntivo, como aquelas encontradas em nosso material. 
SOBEL e MARMORSTON (1956); CLAUSEN (1963) concluiram que o aumento do conteúdo total de colágeno de certos tecidos tem sido encontrado com a variação da idade; também WEZÁR (1969) e DEBESSA et al. (2001) notaram que o aumento de colágeno miocárdico pode contribuir para a diminuição da elasticidade ventricular com a variação da idade; mesmo não encontrando uma correlação clara entre idade e quantidade de tecido conjuntivo, notamos que alguns segmentos possuíam correlação positiva, como por exemplo o ápice, algumas porções dos ventriculos e a parede septal, tal fato é importante pois nos leva a acreditar que com a variação da idade há um aumento progressivo na quantidade de tecido conjuntivo presente no interstício do coração de cães, concordando com as afirmações relatadas, anteriormente.

BADUÍ-DERGAL (1990) notou que algumas enfermidades do tecido conjuntivo podem provocar inflamação e fibrose em qualquer uma das estruturas cardiacas; também WEBER (1989); WEBER e BRILLA (1991) reportaram que várias condições patológicas afetam a função do coração; LUDOVICO (1998) verificou que a hipertrofia ventricular esquerda poderia promover fibrose intersticial, perivascular e acúmulo proporcional ou desproporcional de colágeno; MOORE et al. (1980) observaram que hipertrofia de células musculares são acompanhadas por aumento de tecido conjuntivo; FEIN (1990) notou que cães diabéticos apresentavam aumento de colágeno no interstício cardíaco e diminuição da atividade ventricular.

ABRAHAMS et al. (1987) concluiram que alterações no esqueleto de colágeno que foram observadas nas hipertrofias devem ter um papel 
significativo na diminuição da função ventricular. Também concordamos com o mesmo por acreditar na inter-relação forma e função, portanto modificações que venham a sofrer quaisquer um dos componentes dos tecidos cardíacos podem comprometer toda a atividade do órgão.

No referente as correlações, notamos que nosso trabalho sinaliza a existência de uma distribuição variável de tecido conjuntivo, sem a manutenção de relação específica, quer seja de localização (ventrículo, ápice e septo interventricular), porção (proximal, média e distal) ou camada (superficial e profunda). No entanto algumas correlações indicam relação positiva: entre o peso e a idade do animal com a quantidade de tecido conjuntivo presente no ápice; entre a idade e o septo interventricular; entre a altura ventricular e a espessura ventricular com o septo interventricular; entre as faces esquerdas de ventrículos esquerdo e direito, porção proximal. Outras indicam relação negativa, tais como: peso do animal e a quantidade de tecido conjuntivo presente no septo interventricular; entre a altura ventricular e o ápice. 


\section{CONCLUSÃO}

Em face aos resultados apresentados e os argumentos discutidos viemos por concluir que:

1. Há uma complexa rede de fibras de tecido conjuntivo envolvendo o tecido miocárdico.

2. A quantidade de fibras existentes varia conforme a região, não estabelecendose a predominância evidente entre as porções e as camadas.

3. A quantidade de tecido conjuntivo presente no miocárdio do ventrículo esquerdo de cães variou de $0,97 \%$ a $21,18 \%$.

4. A quantidade de tecido conjuntivo presente no miocárdio do ventrículo direito de cães variou de $0,97 \%$ a $21,18 \%$.

5. A quantidade de tecido conjuntivo presente no ápice do coração de cães variou de $1,32 \%$ a $29,24 \%$.

6. A quantidade de tecido conjuntivo presente no septo interventricular do coração de cães variou de $5,41 \%$ a $11,24 \%$. 


\section{REFERÊNCIAS}

ABRAHAMS, C.; JANICKI, J. S.; WEBER, K. T. Myocardial hypertrophi in Macaca fascicularis: structural remodeling of the collagen matrix. Laboratory Investigation, v. 56, n. 6, p. 676-683, 1987.

ANDERSON, R. H. ; BECKER, A. E.; KIRKLIN, J. W. Atlas de anatomia cardíaca. São Paulo: Santos, 1985, p. 551-567.

BADUÍ-DERGAL, E. El corazón en algunas enfermedades del tejido conectivo. Gaceta Medica de Mexico, v. 126, n. 3, p. 175-189, 1990.

BARGMANN, W. Histología y anatomía microscópica humanas. 3. ed. Barcelona: Labor, 1968, p. 111-147; 311-323.

BEHMER, O. A.; TOLOSA, E. M. C.; FREITAS NETO, A. G. Manual de técnicas para histologia normal e patológica. São Paulo: EDART, Editora da Universidade de São Paulo, 1976, p. 109-128; 174-175; 188.

BARTOSOVA, D; CHVAPIL, M.; KORECKY, B.; POUPA, J. O.; RAKUSAN, K.; TUREK, Z.; VIZEK, M. The growth of the muscular and collagenous parts of the rat heart in various forms of cardiomegaly. Journal of Physiology, v. 200, p. 185-195, 1969.

BORG, T.K.; CAUFIELD, J. B. The collagen matrix of the heart. Federation Proceedings, v. 40, n. 7, p. 2037-2041, 1981.

CAUFIELD, J. B.; BORG, T. K. The collagen network of the heart. Laboratory Investigation, v. 40, n. 3, p. 364-372, 1979.

CLAUSEN, B. Influence of age on chondroitin sulfates and collagen of human aorta, myocardium and skin. Laboratory Investigation, v. 12, p. 538-542, 1963.

CHEITLIN, M. D.; RUBINOWITZ, M.; McALLISTER, H.; HOFFMAN, J. I. E.; BHARATI, S.; LEV, M. The distribuition of fibrosis in the left ventricle in congenital aortic stenosis and coarctation of the aorta. Circulation, v. 62 , p. 823-830, 1980.

DEBESSA, C. R. G.; MAIFRINO, L. B. M.; SOUZA, R. R. Age related changes of the collagen network of the human heart. Mechanisms of Ageing and Development, v. 122, p. 1049-1058, 2001.

DIDIO, L. J. A. Sinopse de anatomia. Rio de Janeiro: Guanabara Koogan, 1974, p. 324-348.

DYCE, K. M.; SACK, W. O.; WENSING, C. J. G. Tratado de Anatomia Veterinária. Rio de Janeiro: Guanabara Koogan, 1987, p. 145-160. 
EGHBALI, M. Collagen gene expression and molecular basis of fibrosis in the myocardium. Heart Failure, v. 6, p. 125-128, 1990.

EGHBALI, M. E.; EGHBALI, M.; ROBINSON, T. F. Collagen accumulation in the heart ventricles as a function of growth and aging. Cardiovasculary Research, v. 23, p. 723-780, 1989.

EVANS, H. E. Miller's anatomy of the dog. 3. ed. Philadelphia: W. B. Saunders, 1993, p. 586-598.

FEIN, F. S. Diabetic Cardiomyopathy. Diabetes Care, v. 13, n.11, p. 1169-1179, 1990.

FRANK, J. S.; LANGER, G. A. The myocardial interstitium: its structure and its role in ionic exchange. The Journal of Cell Biology, v. 60, p. 586-601, 1974.

GARDNER, E.; GRAY, D. J.; O'RAHILLY, R. Anatomia. 3. ed. Rio de Janeiro: Guanabara Koogan, 1971, p. 325-345.

GASPARI, P. G.; GIBSON, K.; HARRIS, P. Changes in myocardial collagen in normal development and after $\beta$-blockade. Journal Molecular Cellular Cardiology, v. 17, p. 456-461, 1985.

GILBERT, P. L.; SIEGEL, R. J.; MELMED, S.; SHERMAN, C. T.; FISHBEIN, M. C. Cardiac morphology in rats with growth hormone producing tumors. Journal Molecular Cellular Cardiology, v. 17, p. 805-811, 1985.

HARVEY, W. Estudo Anatômico sobre o movimento o coração e do sangue nos animais. São Paulo: Universidade de São Paulo. Departamento de Filosofia, 1999, 92 p. (Cadernos de tradução; 5).

JUNQUEIRA, L. C; CARNEIRO, J. Histologia básica. 8. ed. Rio de Janeiro: Guanabara-Koogan, 1995, p. 69-93; 170-173; 187-189.

JUNQUEIRA, L. C. U.; BIGNOLAS, G.; BRENTANI, R. Picrosirius red staining plus polarization microscopy, a specific method for collagen detection in tissue sections. The Histochemical Journal, v. 11, p. 447-455, 1979.

LEGRICE, I. J.; SMAILL, B. H.; CHAI, L. Z; EDGAR, S. G.; GAVIN, J. B.; HUNTER, P. J. Laminar struture of the heart: ventricular myocite arrangement and connective tissue architecture in the dog. American Journal of Physiology, v. 269, p. H571-H582, 1995.

MANDARIM-DE-LACERDA, C. A. Manual de quantificação morfológica: morfometria, alometria e estereologia. 2. ed. Rio de Janeiro: Editora da Universidade Estadual do Rio de Janeiro, 1994, 102 p. 
MEDUCORAC, I. Collagen content in different areas of normal and hyperthophied rat myocardium. Cardiovascular Research, v. 14, p. $551-557,1980$.

MEDUCORAC, I. Caracterization of intramuscular collagen in the mammalian left ventricule. Basic Research in Cardiology, v. 77, p. 589-598, 1982.

MEDUCORAC, I.; JACOB, R. Caracterization of left ventricular collagen in the rat. Cardiovascular Research, v. 17, p. 15-21, 1983.

MICHEL, J. B.; SALZMANN, J. L.; OSSONDO, N. M.; BRUNEVAL, J. P.; BARRES, D.; CAMILLERI, J. P. Morphometric analysis of collagen network and plasma-perfused capillary bed in the myocardium of rats during evolution of cardiac hypertrophy.

Basic Research in Cardiology, v. 81, p. 142-154, 1986.

MOORE, G. W.; HUTCHINS, G. M.; BULKLEY, B. H.; TSENG, J. S.; KI, $P$. F. Constituintes of the human ventricular myocardium: connective tissue hyperplasia accompanying muscular hypertrophy. American Heart Journal, v. 100, n. 5, p. 610-617, 1980.

NICKEL, R.; SCHUMMER, A.; SEIFERLE, E. The anatomy of the domestic animals. v. 3 Berlin: Verlag Paul Parey, 1981, p. 15-38.

OLIVETTI, G.; MELISSARI, M.; CAPASO, J. M.; ANVERSA, P. Cardiomyopathy of aging human heart. Myocyte loss and reactive cellular hypertrophy. Circulation Research, v. 68, p. 1560-1568, 1991.

ROBINSON, T. H.; COHEN-GOULD, L.; FACTOR, S. M. Skeletal framework of mammalian heart muscle. Laboratory Investigation, v. 49 , n. 4 , p. $482-498,1983$.

ROSSI, M. A. Fibrosis and inflamatory cells in human cronic chagasic myocarditis: scanning electron microscopy and immunohistochemical observations. International Journal of Cardiology, v. 66, p. 183-194, 1998.

SÁNCHES-QUINTANA， D.; GÁRCIA-MARTINEZ, V.; CLIMENT, V.; HURLÉ, J. M. Myocardial fiber and connective tissue architecture in the fish heart ventricle. The Journal of Experimental Zoology, v. 275, p. 112-124, 1996.

SÁNCHEZ-QUINTANA, D.; CLIMENT, V.; HO, S. Y.; ANDERSON, R. H. Myoarchitecture and connective tissue in hearts with Tricuspid Atresia. Heart, v. 81, p. 182-191, 1999.

SOBEL, H,; MARMORSTON, J. The possible role of gel-fibre ratio of connective tissue in the aging process. Journal of Gerontology, v. 11, p. 1-7, 1956. 
WEBER, K. T.; CLARK, W. A.; JANICK, J. S.; SHROFF, S. G. Physiologic versus pathologic hypertrophy and the pressure-overload myocardium. Journal of Cardiovascular Pharmacology, v. 10, p. 37-49, 1987.

WEBER, K. T. Cardiac interstitium in health and disease: the fibrillar collagen network. Journal of the American College of Cardiology, v. 13, n. 7 , p. 1637-1652, 1989.

WEBER, K. T.; BRILLA, C. G. Pathological hypertrophy and cardiac interstitium. Cardiology, v. 83, n. 6, p. 1849-1865, 1991.

WEZÁR, F. The stages and consequences of aging of collagen. Gerontologia (Basel), v. 9, p. 209-221, 1964.

WILLIUS, F. A.; DRY, T. J. A history of the heart and the circulation. Philadelphia: W. B. Sauders, 1948, 456 p. 


\section{TABELAS}

TABELA 1.: Valores resultantes da fórmula da Correlação de Pearson entre o Peso do animal e a quantidade de tecido conjuntivo presente nas diversas porções dos Ventrículos. São Paulo - 2002

\begin{tabular}{l|rrrr}
\hline PORÇÃO/FACE & FACE E FPG & FACE E PR & FACE D FPG & FACE D PR \\
\hline PPS VE X P & 0,662902 & $-0,03608$ & $-0,2035$ & $-0,064419$ \\
PPP VE X P & 0,002625 & $-0,05158$ & 0,02652 & $-0,11062$ \\
PMS VE X P & 0,385053 & $-0,22781$ & $-0,33409$ & 0,23555 \\
PMP VE X P & 0,59543 & $-0,013213$ & 0,68964 & 0,44839 \\
PDS VE X P & 0,47607 & 0,071549 & $-0,42572$ & 0,153965 \\
PDP VE X P & 0,12736 & 0,5809 & $-0,107185$ & $-0,61073$ \\
PPS VD X P & 0,0735 & 0,13508 & $-0,121057$ & $-0,30146$ \\
PPP VD X P & $-0,07618$ & $-0,10595$ & $-0,7601$ & 0,34609 \\
PMS VD X P & 0,57085 & 0,71845 & 0,12487 & 0,01175 \\
PMP VD XP & $-0,28931$ & 0,048319 & $-0,7601$ & $-0,22024$ \\
PDS VD X P & $-0,58149$ & $-0,81899$ & 0,103111 & $-0,096229$ \\
PDP VD X P & 0,20281 & 0,34881 & $-0,13342$ & $-0,19899$
\end{tabular}

TABELA 2: Valores resultantes da fórmula da Correlação de Pearson entre o Peso do animal e a quantidade de tecido conjuntivo presente nas diversas porções do Ápice e do Septo Ventricular - São Paulo - 2002

\begin{tabular}{l|rr}
\hline PORÇÃO/COR & \multicolumn{1}{|c}{ FPG } & \multicolumn{1}{c}{ PR } \\
\hline APS X P & 0,709001 & 0,26741 \\
APP X P & 0,58845 & $-0,42019$ \\
SI X P & $-0,35815$ & $-0,65127$
\end{tabular}


TABELA 3: Valores resultantes da fórmula da Correlação de Pearson entre a Idade do animal e a quantidade de tecido conjuntivo presente nas diversas porções dos Ventrículos - São Paulo - 2002

\begin{tabular}{l|rrrr}
\hline PORÇÃO/FACE & FACE E FPG & FACE E PR & FACE D FPG & FACE D PR \\
\hline PPS VE X I & $-0,30796$ & $-0,37876$ & 0,9138 & $-0,09245$ \\
PPP VE X I & $-0,61708$ & 0,50307 & 0,2583 & 0,22981 \\
PMS VE X I & 0,48344 & 0,59665 & 0,36988 & $-0,15438$ \\
PMP VE X I & $-0,0028$ & 0,72885 & 0,21047 & 0,1923 \\
PDS VE X I & 0,42831 & 0,68803 & 0,46438 & 0,71104 \\
PDP VE X I & 0,55487 & 0,45947 & $-0,00049$ & 0,12579 \\
PPS VD X I & $-0,52087$ & $-0,58727$ & $-0,53782$ & 0,35462 \\
PPP VD X I & 0,37427 & 0,41794 & 0,60926 & $-0,03095$ \\
PMS VD X I & 0,37834 & $-0,40892$ & 0,65046 & 0,69446 \\
PMP VD X I & 0,23243 & $-0,20229$ & $-0,66005$ & $-0,18388$ \\
PDS VD X I & 0,4326 & $-0,07457$ & $-0,05742$ & $-0,14358$ \\
PDP VD X I & 0,076774 & 0,26763 & 0,54741 & 0,33347
\end{tabular}

TABELA 4: Valores resultantes da fórmula da Correlação de Pearson entre a Idade do animal e a quantidade de tecido conjuntivo presente nas diversas porções do Ápice e do Septo Ventricular - São Paulo - 2002

\begin{tabular}{l|rr}
\hline PORÇÃO/COR & \multicolumn{1}{|l}{ FPG } & PR \\
\hline APS X I & 0,10411 & 0,46632 \\
APP X I & $-0,07862$ & 0,59266 \\
SI X I & 0,57751 & 0,63488
\end{tabular}


TABELA 5: Valores resultantes da fórmula da Correlação de Pearson entre a Altura Ventricular do coração de cada animal e a quantidade de tecido conjuntivo presente nas diversas porções dos Ventrículos - São Paulo - 2002

\begin{tabular}{l|rrrr}
\hline PORÇÃO/FACE & FACE E FPG & FACE E PR & FACE D FPG & FACE D PR \\
\hline PPS VE X AV & $-0,48505$ & $-0,49825$ & $-0,13012$ & $-0,036998$ \\
PPP VE X AV & $-0,25242$ & $-0,50443$ & $-0,29247$ & $-0,4337$ \\
PMS VE X AV & $-0,36427$ & 0,04394 & 0,51479 & $-0,76489$ \\
PMP VE X AV & $-0,14462$ & 0,33676 & 0,086333 & $-0,0494$ \\
PDS VE X AV & $-0,2752$ & 0,5251 & 0,40658 & $-0,32046$ \\
PDP VE X AV & $-0,26569$ & $-0,29142$ & $-0,09846$ & $-0,024032$ \\
PPS VD X AV & $-0,20121$ & $-0,37956$ & 0,03262 & $-0,16139$ \\
PPP VD X AV & $-0,37207$ & 0,11419 & 0,71916 & 0,29369 \\
PMS VD X AV & $-0,37338$ & $-0,77192$ & $-0,30043$ & $-0,4396$ \\
PMP VD X AV & 0,90677 & 0,61356 & 0,05276 & $-0,51456$ \\
PDS VD X AV & 0,26767 & 0,543226 & 0,8249 & 0,46048 \\
PDP VD X AV & $-0,17171$ & $-0,4383$ & 0,14187 & $-0,25219$
\end{tabular}

TABELA 6: Valores resultantes da fórmula da Correlação de Pearson entre a Altura Ventricular do coração de cada animal e a quantidade de tecido conjuntivo presente nas diversas porções do Ápice e do Septo Ventricular - São Paulo - 2002

\begin{tabular}{l|lr}
\hline PORÇÃO/COR & FPG & \multicolumn{1}{l}{ PR } \\
\hline APS X AV & $-0,31636$ & $-0,54599$ \\
APP X AV & $-0,83313$ & $-0,26679$ \\
SI X AV & 0,53907 & 0,03181
\end{tabular}


TABELA 7: Valores resultantes da fórmula da Correlação de Pearson entre a Espessura Ventricular Esquerda do coração de cada animal e a quantidade de tecido conjuntivo presente nas diversas porções dos Ventrículos - São Paulo - 2002

\begin{tabular}{l|rrrr}
\hline PORÇÃO/FACE & FACE E FPG & FACE E PR & FACE D FPG & FACE D PR \\
\hline PPS VE X EV & 0,11627 & 0,148327 & 0,38166 & $-0,04375$ \\
PPP VE X EV & $-0,26487$ & 0,26851 & $-0,6083$ & 0,31474 \\
PMS VE X EV & 0,30228 & 0,7445 & 0,34071 & $-0,59767$ \\
PMP VE X EV & 0,09639 & 0,30203 & 0,50958 & 0,62864 \\
PDS VE X EV & 0,14593 & 0,23551 & $-0,49513$ & 0,05836 \\
PDP VE X EV & $-0,21047$ & 0,47284 & $-0,79375$ & 0,367
\end{tabular}

TABELA 8: Valores resultantes da fórmula da Correlação de Pearson entre a Espessura Ventricular Direita do coração de cada animal e a quantidade de tecido conjuntivo presente nas diversas porções dos Ventrículos - São Paulo - 2002

\begin{tabular}{l|rrrr}
\hline PORÇÃO/FAC & FACE E FPG & FACE E PR & FACE D FPG & FACE D PR \\
E & & & & \\
\hline PPS VD X EV & $-0,0866$ & $-0,25729$ & $-0,28078$ & $-0,26322$ \\
PPP VD X EV & $-0,25852$ & 0,368739 & 0,546358 & 0,46466 \\
PMS VD X EV & $-0,10213$ & $-0,49357$ & $-0,18431$ & $-0,3557$ \\
PMP VD X EV & 0,74701 & 0,464512 & 0,29247 & $-0,51615$ \\
PDS VD X EV & 0,24087 & 0,19695 & 0,80326 & 0,3701 \\
PDP VD X EV & $-0,05873$ & $-0,25575$ & 0,339 & $-0,15765$
\end{tabular}

TABELA 9: Valores resultantes da fórmula da Correlação de Pearson entre a Espessura Ventricular do coração de cada animal e a quantidade de tecido conjuntivo presente nas diversas porções do Ápice e do Septo Interventricular - São Paulo - 2002

\begin{tabular}{l|rrrr}
\hline PORÇÃO/COR & \multicolumn{1}{|c}{ FPG VE } & FPG VD & \multicolumn{1}{c}{ PR VE } & \multicolumn{1}{c}{ PR VD } \\
\hline APS X EV & 0,48609 & $-0,14276$ & $-0,03176$ & $-0,44836$ \\
APP X EV & 0,09775 & $-0,73559$ & 0,50161 & $-0,1898$ \\
SI X EV & 0,6182 & 0,51008 & 0,33914 & 0,06406
\end{tabular}


TABELA 10: Valores resultantes da fórmula da Correlação de Pearson entre a quantidade de tecido conjuntivo presente nas diversas porções do Ventrículo Esquerdo e do Direito São Paulo - 2002

\begin{tabular}{l|rrrr}
\hline PORÇÃO/COR & \multicolumn{1}{|c}{ FPG FE } & \multicolumn{1}{c}{ PR FE } & \multicolumn{1}{c}{ FPG FD } & \multicolumn{1}{c}{ PR FD } \\
\hline PPS X PPS & 0,709271495 & 0,756229921 & $-0,666827519$ & $-0,488547242$ \\
PPP X PPP & 0,404764411 & 0,700861332 & $-0,244424867$ & $-0,898647469$ \\
PMS X PMS & 0,365367779 & $-0,213354011$ & 0,425370556 & 0,287752011 \\
PMP X PMP & 0,227234285 & 0,13457071 & 0,540266441 & $-0,779243073$ \\
PDS X PDS & $-0,505867208$ & $-0,123658714$ & 0,225150578 & 0,012879091 \\
PDP X PDP & 0,04550661 & 0,215235721 & $-0,513290018$ & $-0,002650177$
\end{tabular}

TABELA 11: Valores resultantes da fórmula da Correlação de Pearson entre a quantidade de tecido conjuntivo presente nas diversas porções dentro do mesmo Ventrículo - São Paulo - 2002

\begin{tabular}{l|rrrr}
\hline PORÇÃO/ COR & FACE E FPG & FACE E PR & FACE D FPG & FACE D PR \\
\hline PPS VE X PMS VE & $-0,15646$ & 0,01086 & 0,03809 & 0,54982 \\
PPP VE X PMP VE & $-0,71468$ & $-0,11606$ & 0,05826 & 0,60094 \\
PPS VE X PDS VE & $-0,13063$ & $-0,74306$ & 0,31157 & $-0,20964$ \\
PPP VE X PDP VE & $-0,69948$ & 0,20436 & 0,6414 & 0,66502 \\
PMS VE X PDS VE & 0,95752 & 0,05236 & 0,09333 & 0,34459 \\
PMP VE X PDP VE & 0,54106 & 0,69292 & $-0,41272$ & 0,10494 \\
& & & & \\
PPS VD X PMS VD & 0,18635 & 0,64028 & $-0,45564$ & 0,67352 \\
PPP VD X PMP VD & $-0,58211$ & $-0,27212$ & $-0,56248$ & 0,12259 \\
PPS VD X PDS MD & 0,46737 & $-0,13407$ & 0,20883 & 0,52046 \\
PPP VD X PDP VD & 0,81983 & 0,6218 & 0,0639 & 0,42229 \\
PMS VD X PDS VD & 0,21029 & $-0,79508$ & $-0,31647$ & $-0,14227$ \\
PMP VD X PDP VD & $-0,33884$ & $-0,14152$ & $-0,11168$ & 0,79935
\end{tabular}


TABELA 12: Valores resultantes da fórmula da Correlação de Pearson entre a quantidade de tecido conjuntivo presente na face esquerda e direita do mesmo Ventrículo - São Paulo $-2002$

\begin{tabular}{l|rr}
\hline FACE/COR & \multicolumn{1}{c}{ FPG } & \multicolumn{1}{c}{ PR } \\
\hline PPS VE X PPS VE & $-0,00771$ & $-0,02252$ \\
PPP VE X PPP VE & 0,00133 & 0,19588 \\
PMS VE X PMS VE & 0,39853 & $-0,17089$ \\
PMP VE X PMP VE & 0,23198 & 0,59455 \\
PDS VE X PDS VE & 0,13854 & 0,57266 \\
PDP VE X PDP VE & 0,69243 & $-0,23247$ \\
PPS VD X PPS VD & $-0,16884$ & 0,33484 \\
PPP VD X PPP VD & $-0,26608$ & 0,54169 \\
PMS VD X PMS VD & 0,37725 & 0,25446 \\
PMP VD X PMP VD & $-0,01729$ & $-0,30274$ \\
PDS VD X PDS VD & $-0,19751$ & 0,3429 \\
PDP VD X PDP VD & 0,70746 & 0,82704
\end{tabular}

TABELA 13: Valores resultantes da fórmula da Correlação de Pearson entre a quantidade de tecido conjuntivo presente no Ápice e nos Ventrículos - São Paulo - 2002

\begin{tabular}{l|rr}
\hline PORÇÃO/APICE & FPG & PR \\
\hline PPS VE FE & 0,10702 & 0,04802 \\
PPP VE FE & $-0,23379$ & 0,7454 \\
PMS VE FE & 0,83489 & $-0,07196$ \\
PMP VE FE & 0,61982 & 0,09629 \\
PDS VE FE & 0,800002 & 0,33506 \\
PDP VE FE & 0,44279 & 0,18196 \\
PPS VE FD & 0,100244 & $-0,28645$ \\
PPP VE FE & 0,03455 & 0,65791 \\
PMS VE FD & 0,3244 & 0,4126 \\
PMP VE FD & 0,05814 & 0,12546 \\
PDS VE FD & $-0,44742$ & 0,93232 \\
PDP VE FD & 0,11032 & 0,75133 \\
PPS VD FE & $-0,58468$ & 0,16972 \\
PPP VD FE & $-0,02388$ & 0,47809 \\
PMS VD FE & 0,35261 & 0,43943 \\
PMP VD FE & $-0,60213$ & $-0,86183$ \\
PDS VD FE & $-0,77672$ & $-0,55511$ \\
PDP VD FE & $-0,21848$ & 0,17044 \\
PPS VD FD & $-0,14081$ & 0,71677 \\
PPP VD FE & $-0,50421$ & $-0,45614$ \\
PMS VD FD & 0,69689 & 0,93256 \\
PMP VD FD & 0,01086 & 0,28312 \\
PDS VD FD & 0,08521 & 0,04396 \\
PDP VD FD & $-0,36815$ & 0,4393
\end{tabular}


TABELA 14: Valores resultantes da fórmula da Correlação de Pearson entre a quantidade de tecido conjuntivo presente no Septo Interventricular e nos Ventrículos - São Paulo 2002

\begin{tabular}{l|rr}
\hline PORÇÃO/SEPTO & FPG & PR \\
\hline PPS VE FE X SI & $-0,70094$ & 0,38859 \\
PPS VD FE X SI & $-0,80841$ & 0,070525 \\
PPP VE FE X SI & $-0,74566$ & 0,74739 \\
PPP VD FE X SI & $-0,45853$ & 0,701443 \\
PMS VE FE X SI & 0,39347 & 0,46028 \\
PMS VD FE X SI & $-0,28228$ & $-0,15141$ \\
PMP VE FE X SI & 0,2985 & $-0,02257$ \\
PMP VD FE X SI & 0,58889 & $-0,54368$ \\
PDS VE FE X SI & 0,28573 & 0,05068 \\
PDS VD FE X SI & $-0,17001$ & 0,10854 \\
PDP VE FE X SI & 0,11599 & $-0,16667$ \\
PDP VD FE X SI & $-0,69759$ & 0,29735 \\
PPS VE FD X SI & 0,28482 & $-0,17115$ \\
PPS VD FD X SI & $-0,13247$ & 0,48025 \\
PPP VE FD X SI & $-0,52952$ & 0,22245 \\
PPP VD FD X SI & 0,83811 & $-0,10935$ \\
PMS VE FD X SI & 0,9301 & $-0,27315$ \\
PMS VD FD X SI & 0,5726 & 0,605006 \\
PMP VE FD X SI & $-0,05874$ & $-0,29669$ \\
PMP VD FD X SI & $-0,30183$ & 0,46026 \\
PDS VE FD X SI & 0,02088 & 0,35113 \\
PDS VD FD X SI & 0,377009 & $-0,15111$ \\
PDP VE FD X SI & $-0,1632$ & 0,610719 \\
PDP VD FD X SI & $-0,070706$ & 0,70064
\end{tabular}

TABELA 15: Valores resultantes da fórmula da Correlação de Pearson entre a quantidade de tecido conjuntivo presente no Septo Interventricular e no Ápice - São Paulo - 2002

\begin{tabular}{l|rr}
\hline PORÇÃO/COR & FPG & PR \\
\hline APS X SI & 0,31991 & 0,3357 \\
APP X SI & $-0,10133$ & 0,86219
\end{tabular}


TABELA 16: Resumo dos valores mínimo e máximo encontrados para cada um dos ventrículos, ápice e septo interventricular - São Paulo - 2002

VALORES MÍNIMOS E MÁXIMOS ENCONTRADOS (\%)

\begin{tabular}{l|rr}
\hline FACE/VALOR & MÍNIMO & MÁXIMO \\
\hline VEFEFPG & 0,44 & 19,69 \\
VEFEPR & 1,33 & 23,59 \\
VEFDFPG & 2,31 & 16,39 \\
VEFDPR & 2,21 & 26,26 \\
VDFEFPG & 1,75 & 18,85 \\
VDFEPR & 1,77 & 21,18 \\
FVDFDFPG & 0,97 & 18,44 \\
VDFDPR & 1,32 & 18,12 \\
& & \\
APFPG & 1,32 & 13,40 \\
APPR & 1,35 & 29,24 \\
& & \\
SIFPG & 6,76 & 11,24 \\
SIPR & 5,41 & 9,60
\end{tabular}



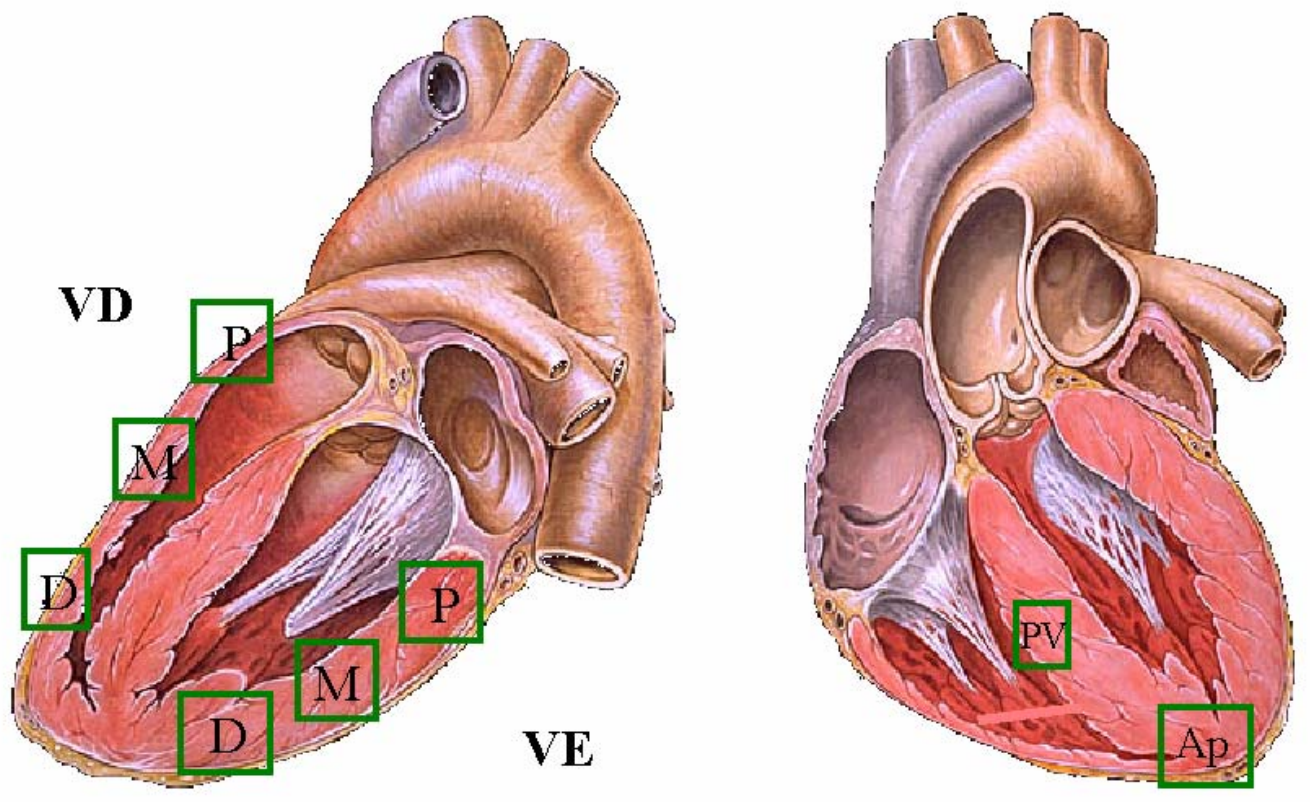

FIGURA 1: Desenho esquemático representando as porções: proximal $(P)$, média $(M)$ e distal (D) dos ventrículos; parede ventricular (PV) e ápice (Ap). 


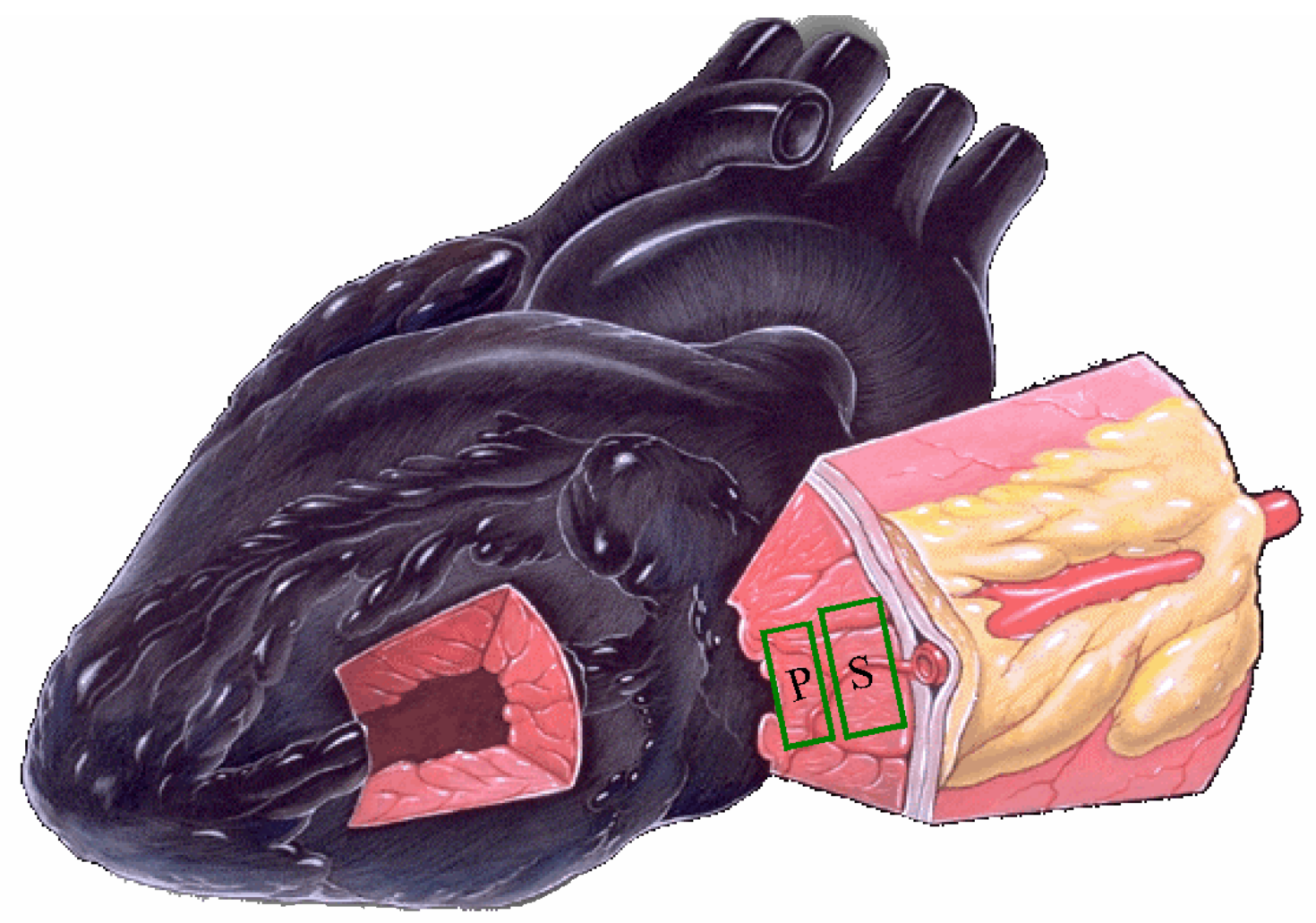

FIGURA 2: Desenho esquemático representando as camadas: superficial (S) e profunda $(P)$ dos ventrículos. 


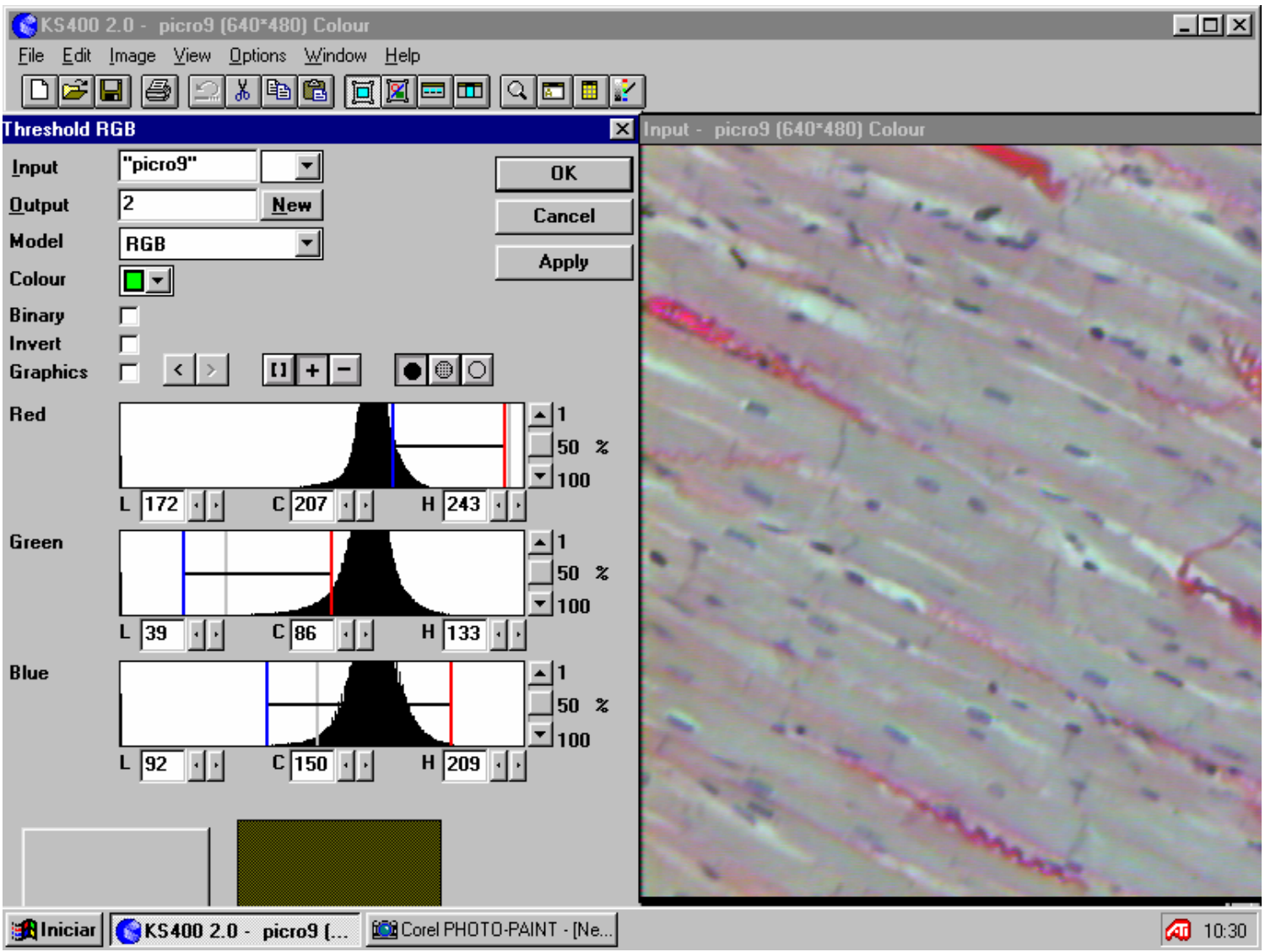

FIGURA 3: Foto representando captura de imagem no Programa KS400 Zeiss ${ }^{\circledR}$ 


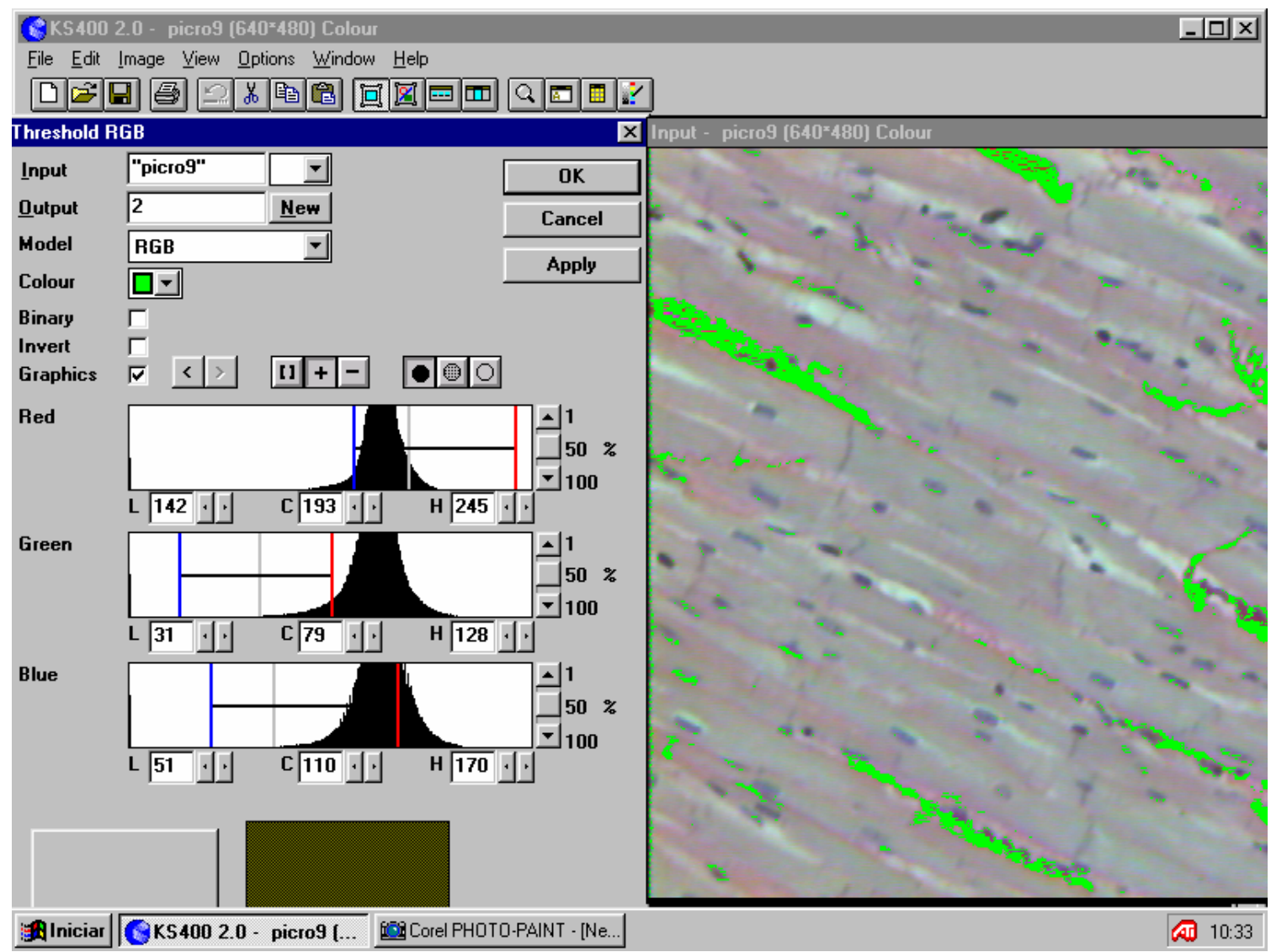

FIGURA 4: Foto representando a identificação da freqüência da cor desejada no Programa KS400 Zeiss ${ }^{\circledR}$ 


\section{CKS400 2.0 - picro9 [640×480] Colour}

File Edit Image View Qptions Window Help

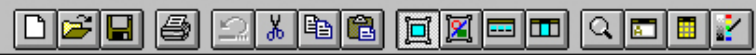

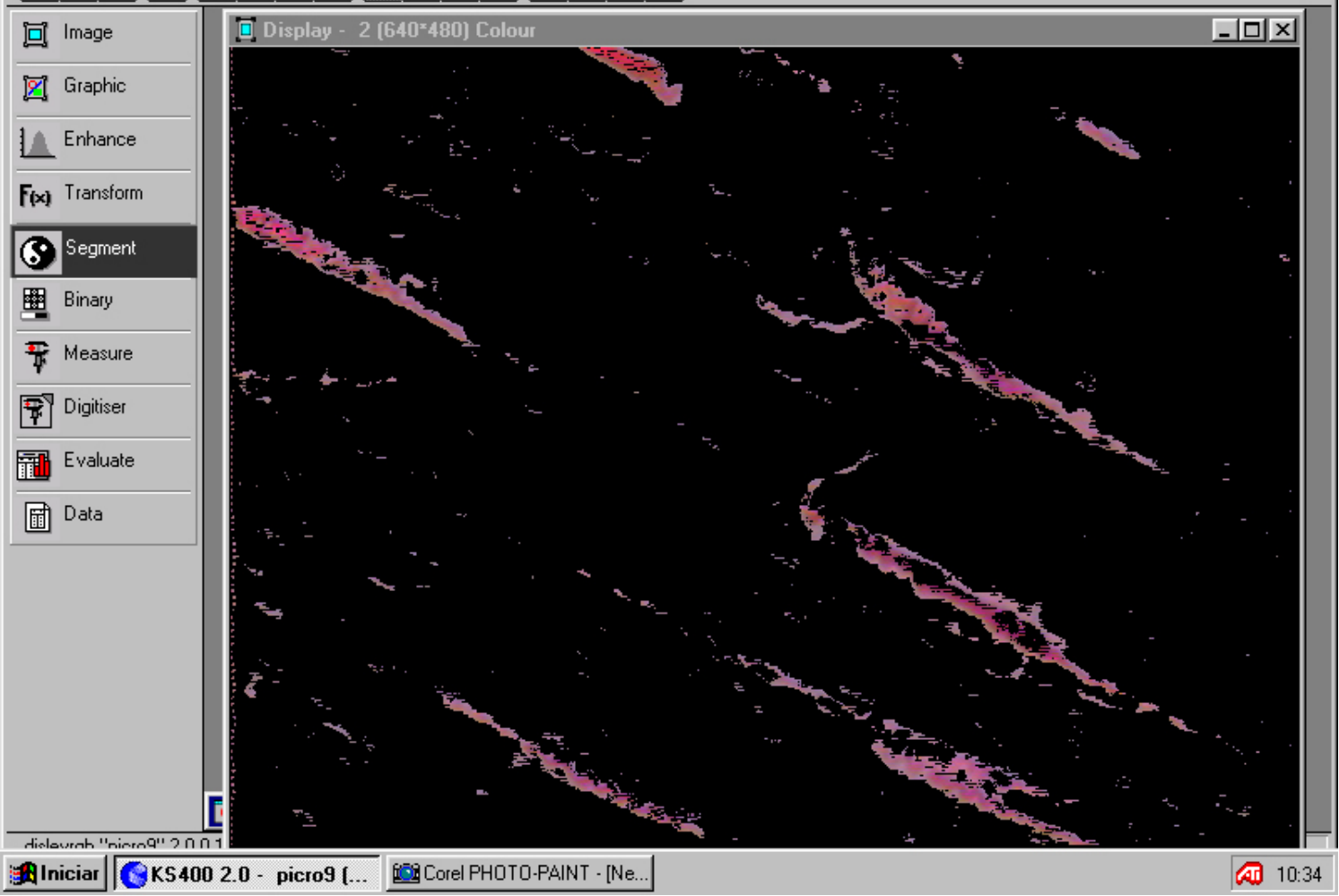

FIGURA 5: Foto representando a seleção da cor previamente identificada no Programa KS400 Zeiss ${ }^{\circledR}$ 


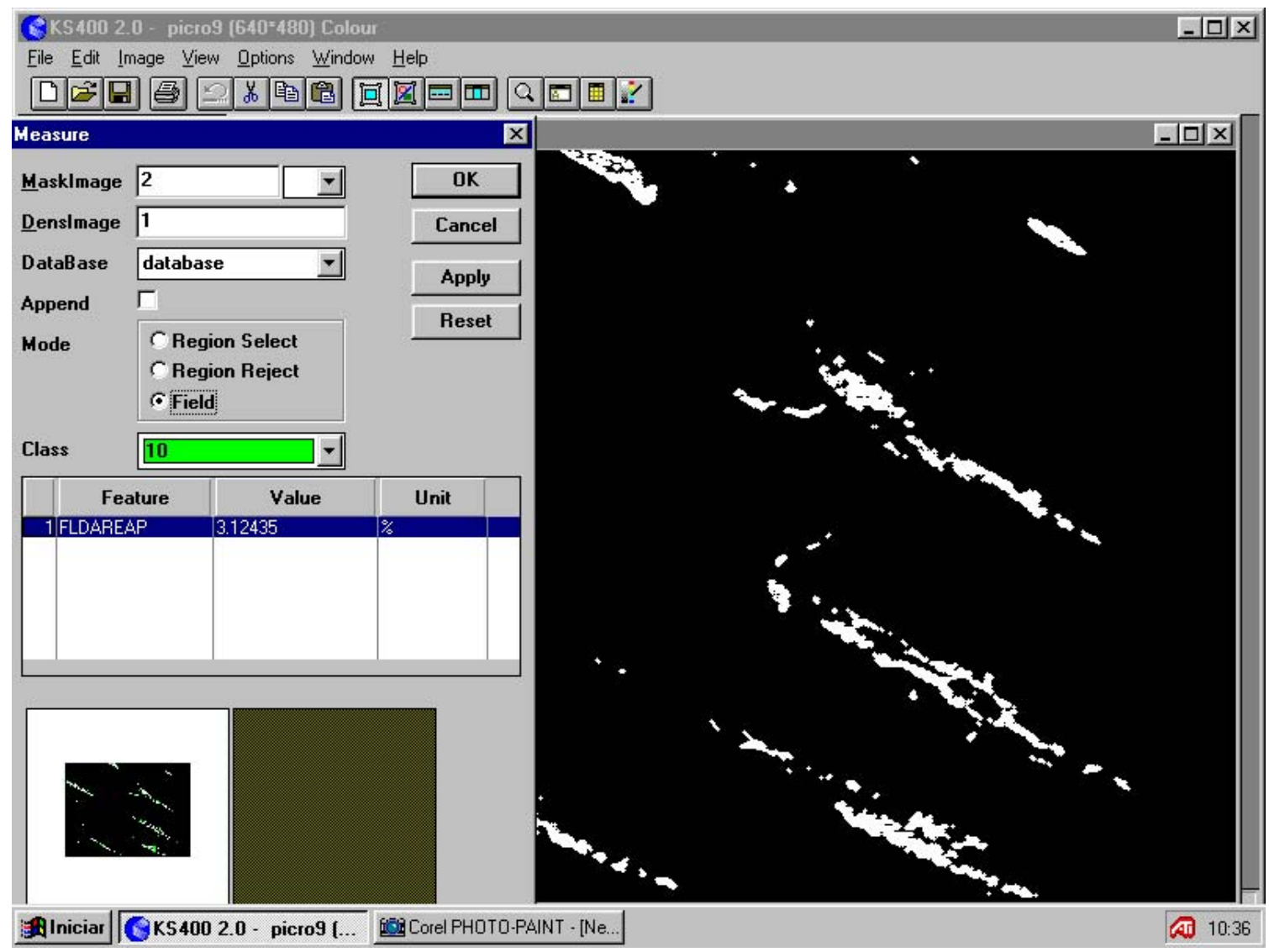

FIGURA 6: Foto representando a binarização da imagem e a mensuração do campo selecionado no Programa KS400 Zeiss ${ }^{\circledR}$ 


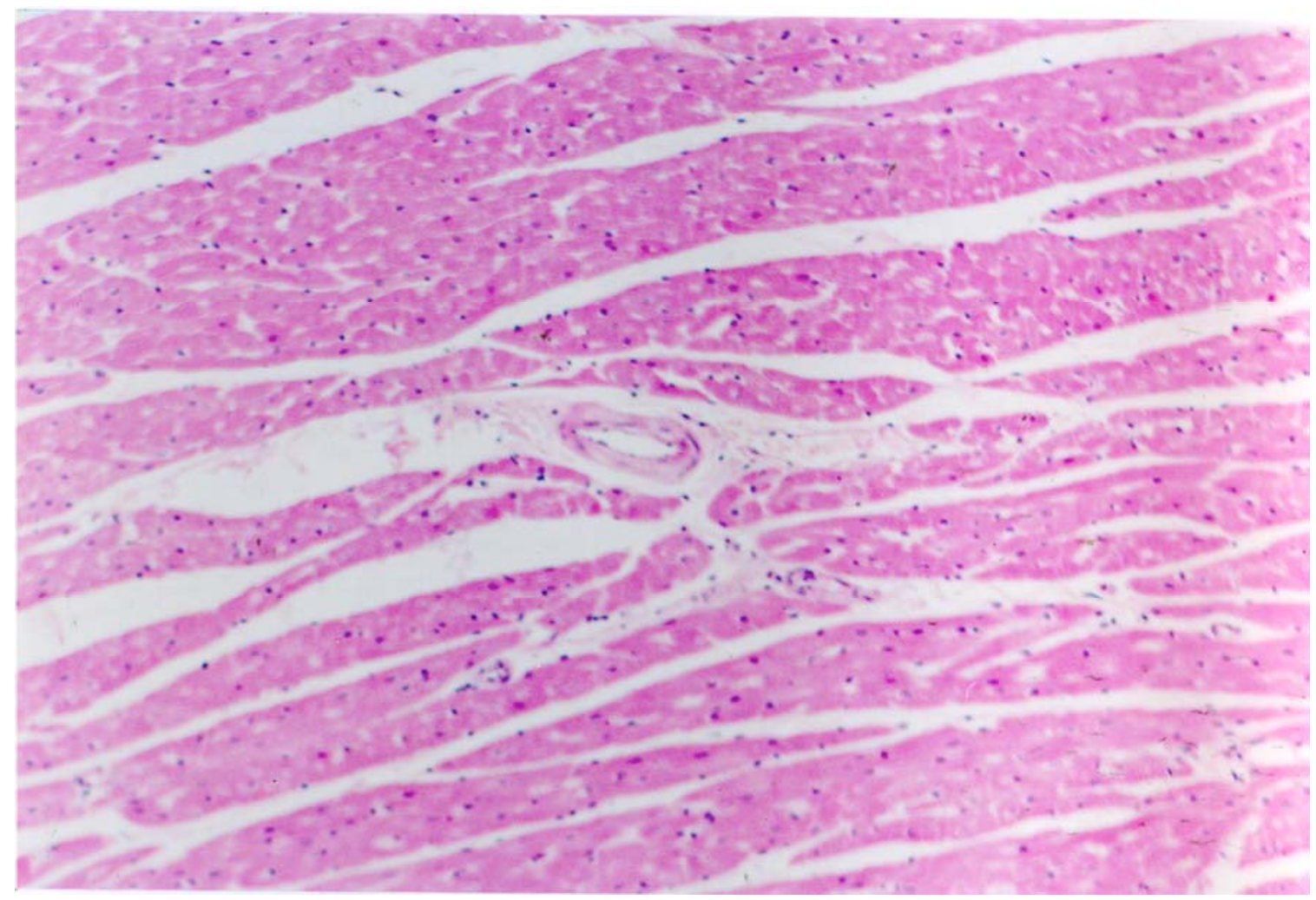

FIGURA 7: Foto de corte transversal de fragmento de ventrículo direito, técnica de coloração: Hematoxilina-Eosina, 100X 


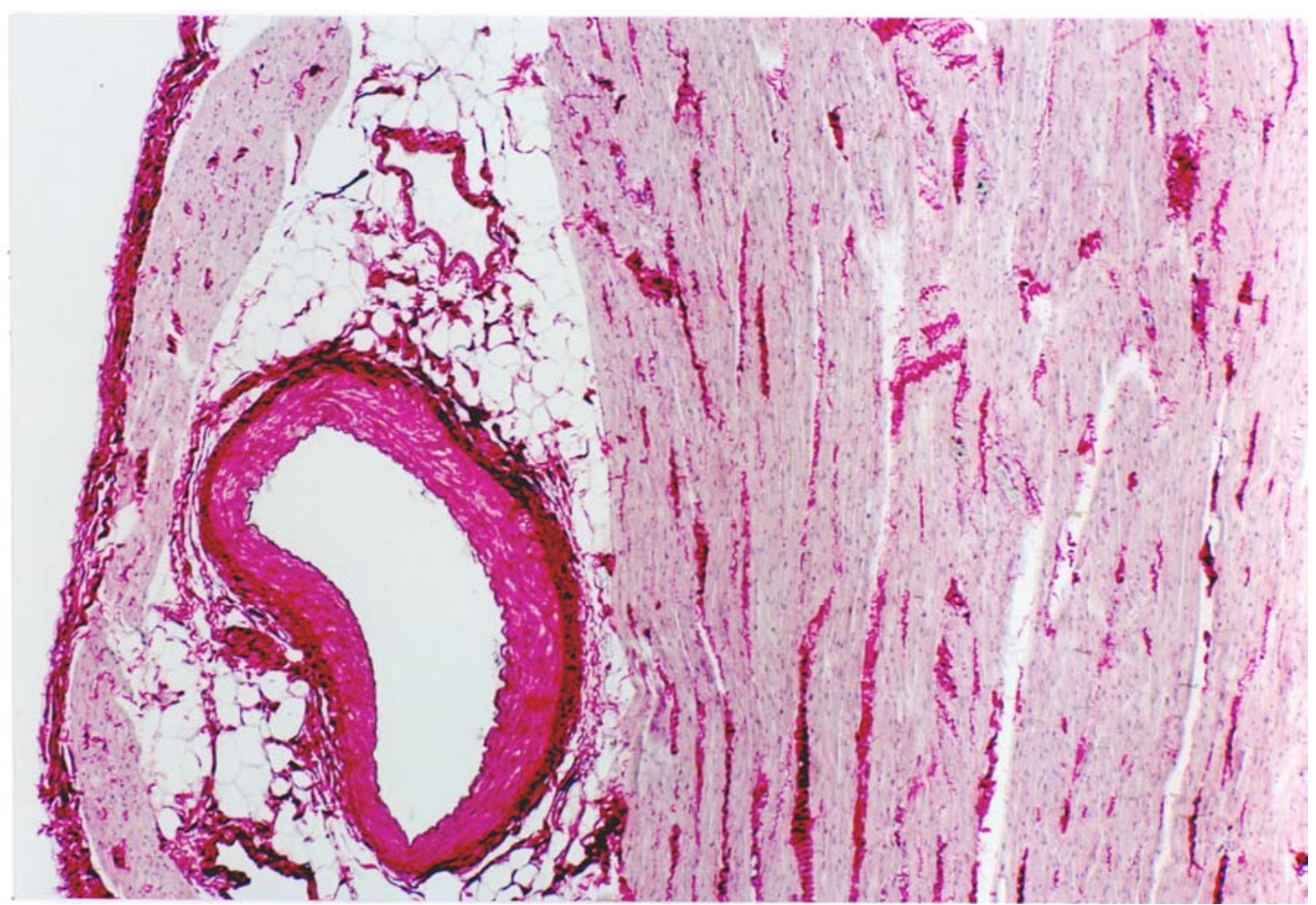

FIGURA 8: Foto de corte transversal de fragmento de ventrículo esquerdo, técnica de coloração: Picrosirius red, 50X 


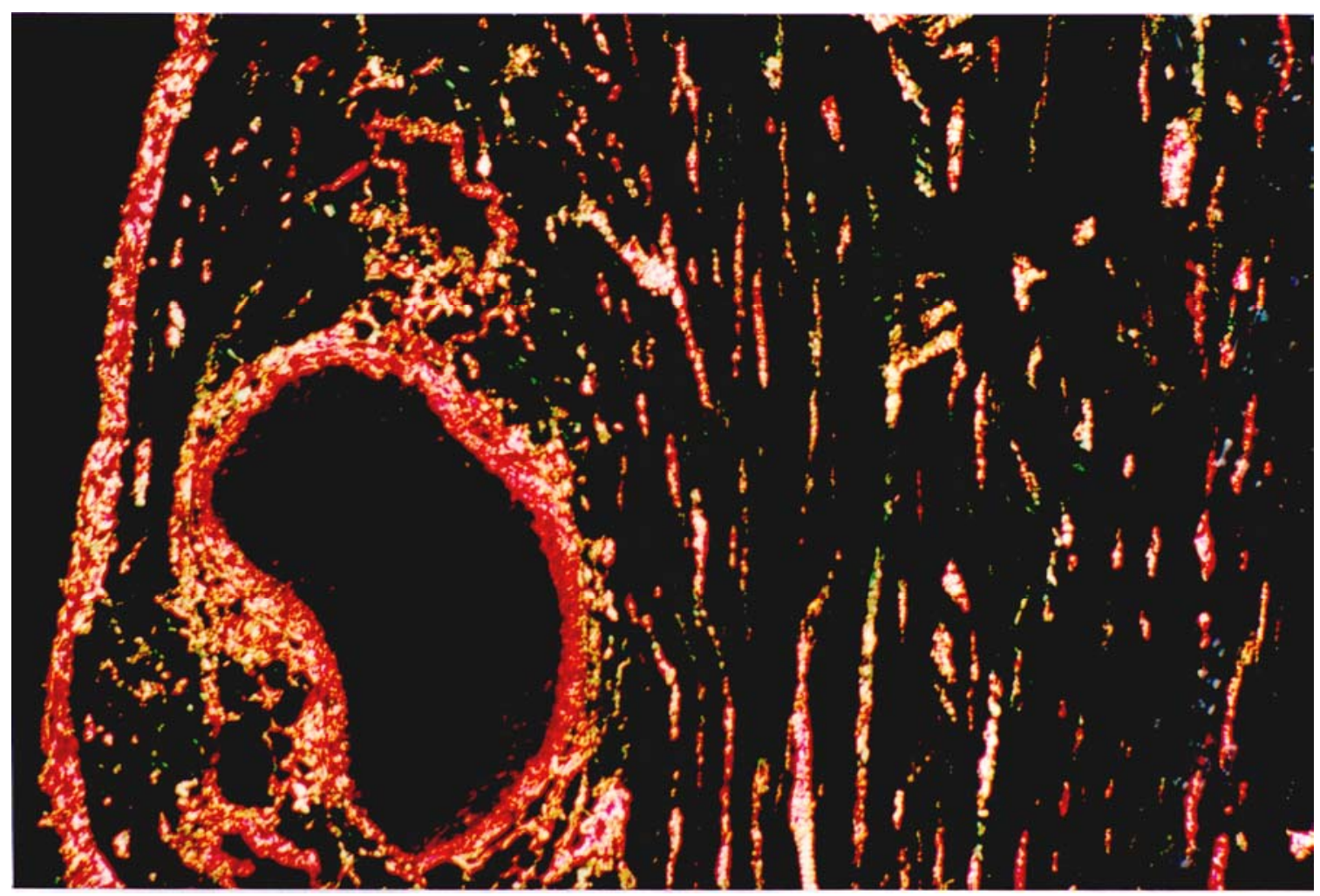

FIGURA 9: Foto de corte transversal de fragmento de ventrículo esquerdo, técnica de coloração: Picrosirius red, filtro polarizado, 50X. 


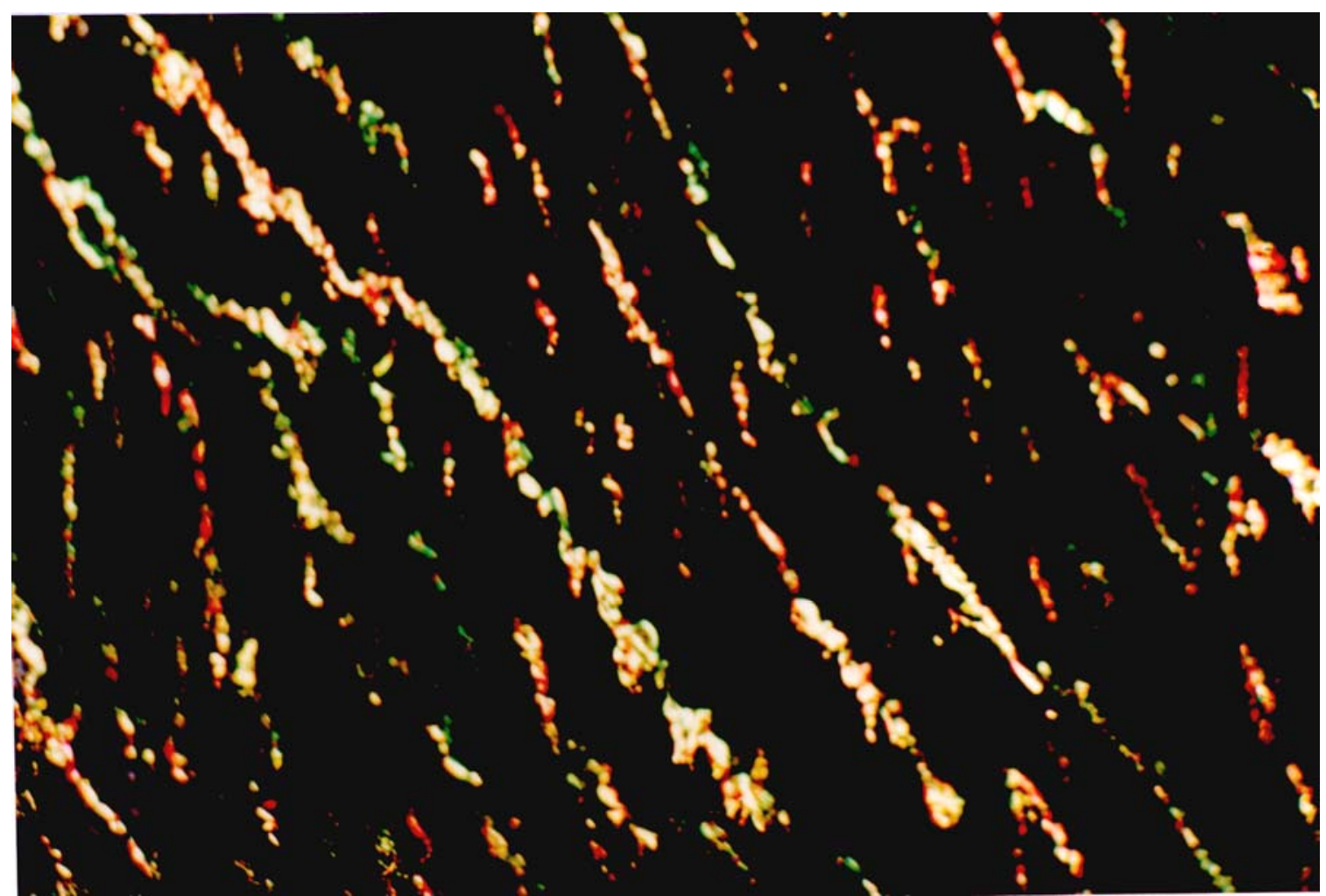

FIGURA 10: Foto de corte transversal de fragmento de ventrículo esquerdo, técnica de coloração: Picrosirius red, filtro polarizado, 100X. 


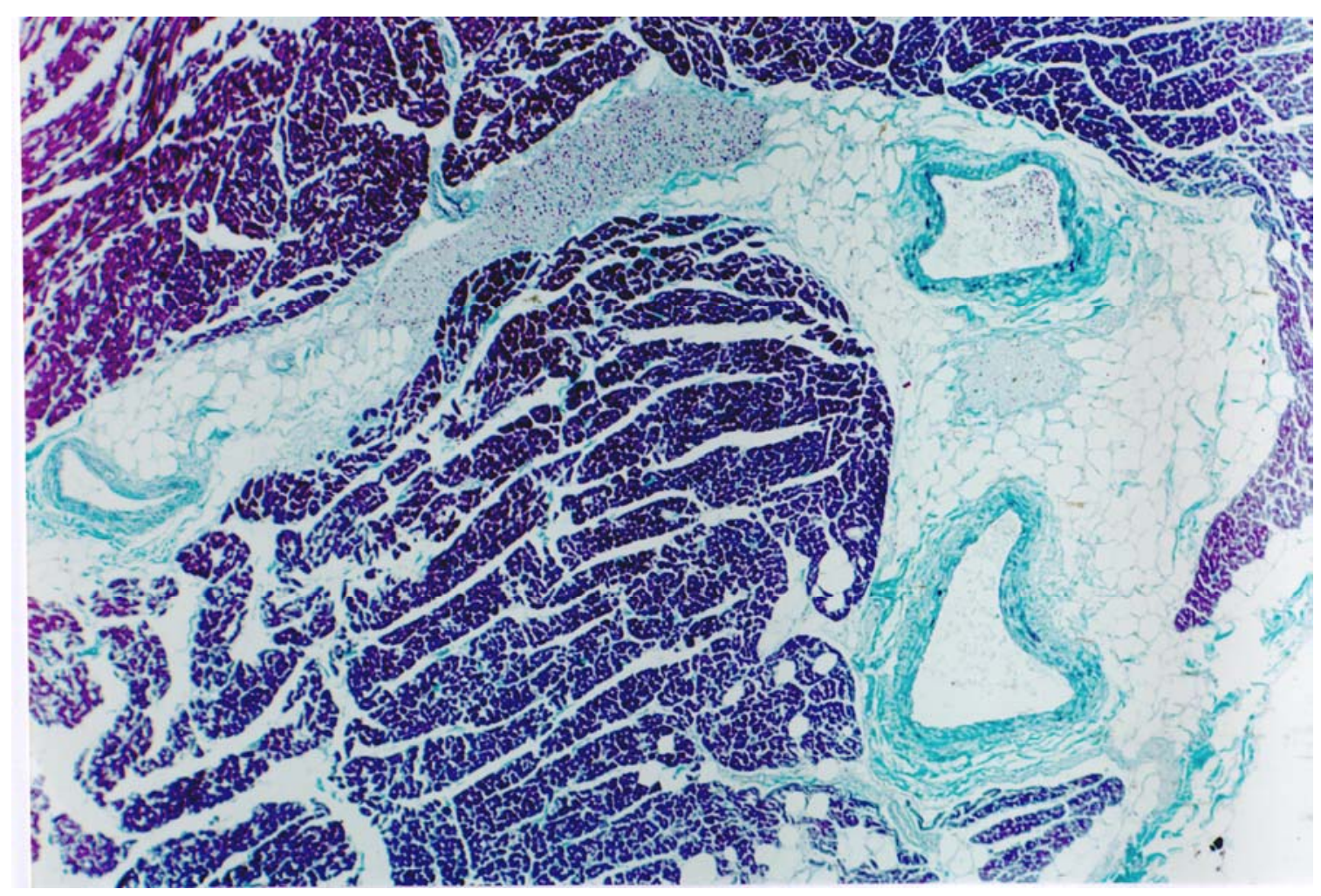

FIGURA 11: Foto de corte transversal de fragmento de ventrículo esquerdo, técnica de coloração: Fucsina-Paraldeido + Tricromo Gomori, 25X. 


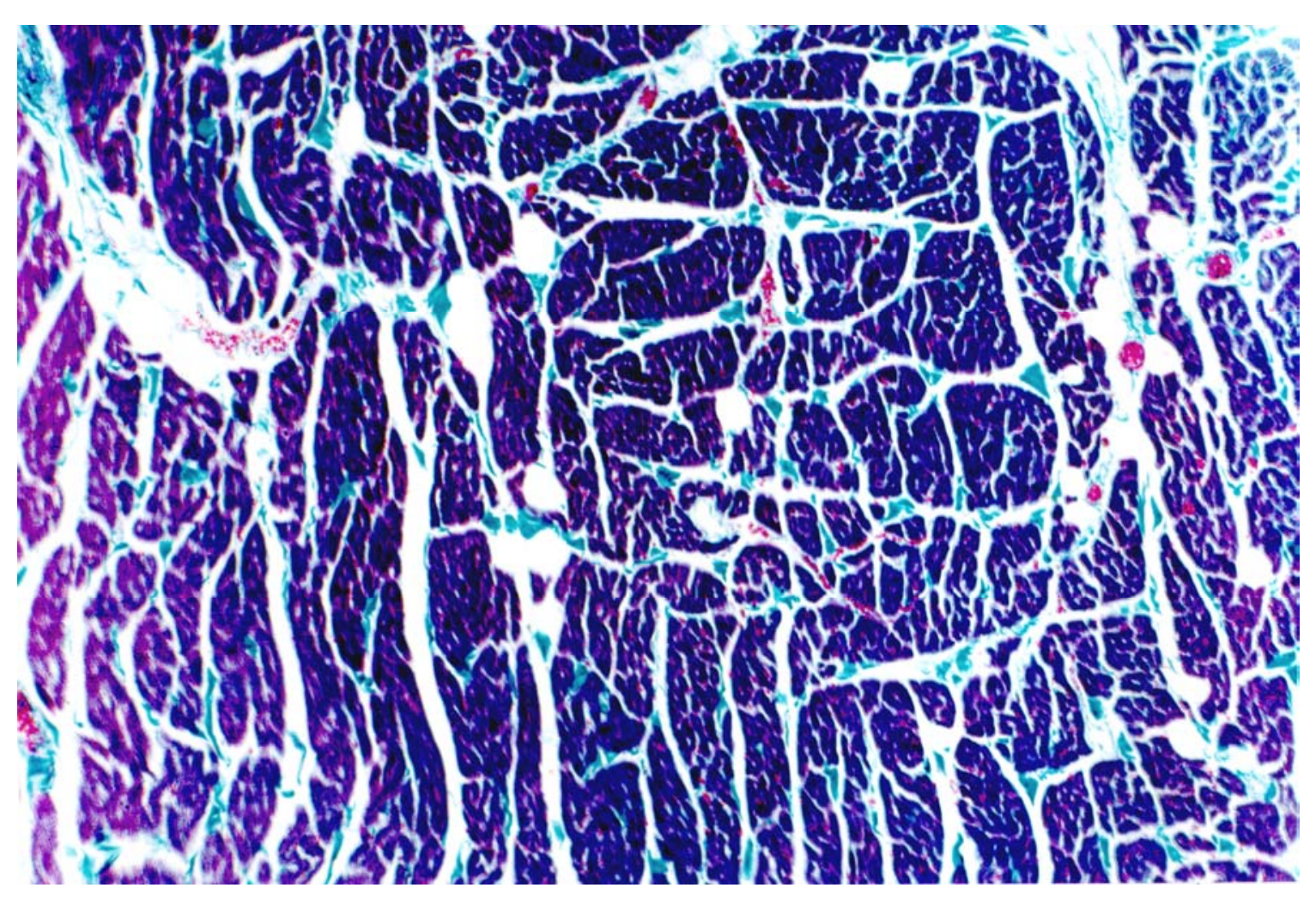

FIGURA 12: Foto de corte transversal de fragmento de ventrículo esquerdo, técnica de coloração: Fucsina-Paraldeido + Tricromo Gomori, 50X. 


\section{FICHA PROTOCOLO}

Pesquisa título:

no.

Identificação do Animal

Nome:

no. de prontuário:

Origem:

Causa Mortis:

Sexo:

Idade:

Dados Biométricos

Peso do Animal:

Altura Ventricular:

Espessura de Ventrículo Esquerdo:

Espessura de Ventrículo

Direito:

Dados Clínicos

Histórico:

Exames Complementares (avaliação cardiaca)

1. RX laudo:

2. Eletrocardiograma laudo:

3. Ecocardiograma laudo: 